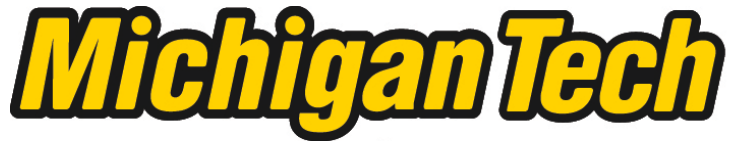 \\ Michigan Technological University Create the Future Digital Commons @ Michigan Tech
}

Dissertations, Master's Theses and Master's Reports - Open

Dissertations, Master's Theses and Master's

Reports

2015

\section{DON'T GET TESTY ABOUT IT: CAN TEACHING CRITICAL THINKING SKILLS IMPROVE ACT SCORES?}

Glenda L. LaBruyere

Michigan Technological University

Follow this and additional works at: https://digitalcommons.mtu.edu/etds

Part of the Educational Assessment, Evaluation, and Research Commons Copyright 2015 Glenda L. LaBruyere

\section{Recommended Citation}

LaBruyere, Glenda L., "DON'T GET TESTY ABOUT IT: CAN TEACHING CRITICAL THINKING SKILLS IMPROVE ACT SCORES?", Master's report, Michigan Technological University, 2015.

https://doi.org/10.37099/mtu.dc.etds/987

Follow this and additional works at: https://digitalcommons.mtu.edu/etds

Part of the Educational Assessment, Evaluation, and Research Commons 


\title{
DON'T GET TESTY ABOUT IT: CAN TEACHING CRITICAL THINKING SKILLS
} IMPROVE ACT SCORES?

\author{
By \\ Glenda L. LaBruyere
}

\begin{abstract}
A REPORT
Submitted in partial fulfillment of the requirements for the degree of MASTER OF SCIENCE

In Applied Science Education
\end{abstract}

MICHIGAN TECHNOLOGICAL UNIVERSITY

2015

(C) 2015 Glenda L. LaBruyere 
This report has been approved in partial fulfillment of the requirements for the Degree of MASTER OF SCIENCE in Applied Science Education.

Department of Cognitive and Learning Sciences

Report Advisor: Shari Stockero, Ph.D.

Committee Member: Susan Amato-Henderson, Ph.D.

Committee Member: $\quad$ Alexandria Guth, Ph.D.

Department Chair: Susan Amato-Henderson, Ph.D. 


\section{Table of Contents}

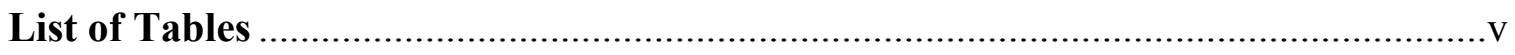

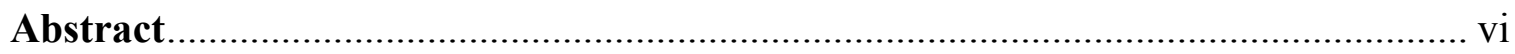

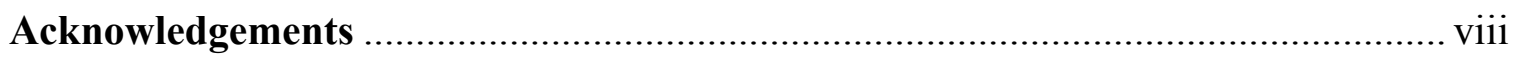

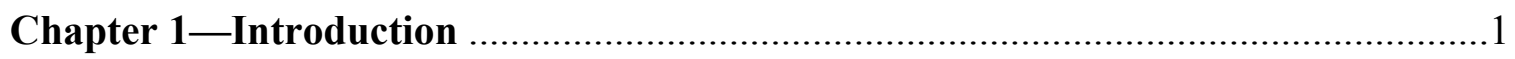

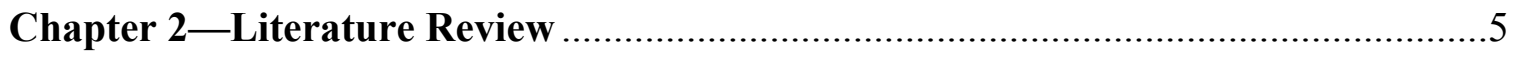

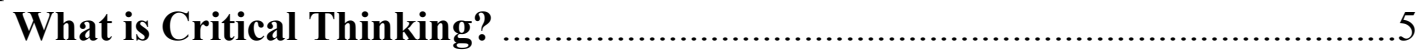

How is Critical Thinking Measured? ..............................................................

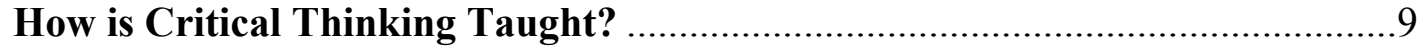

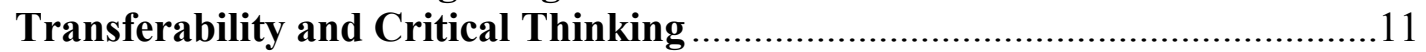

Argumentation as a Critical Thinking Skill ........................................................ 13

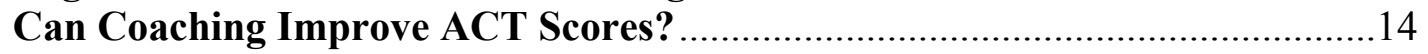

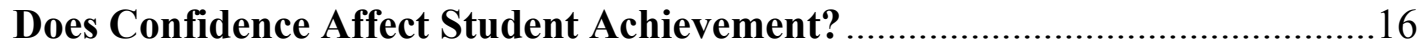

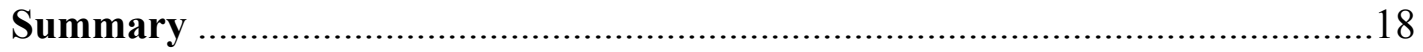

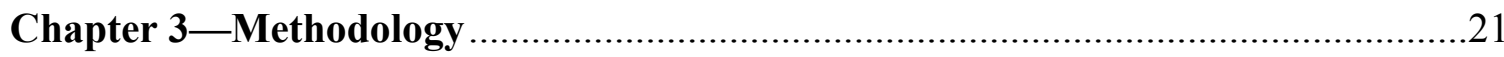

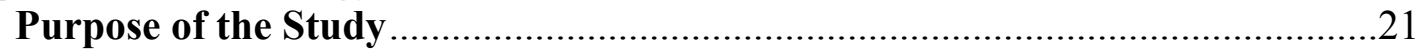

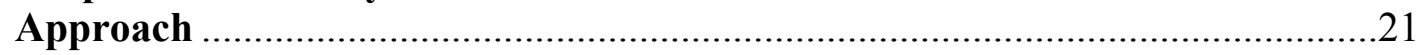

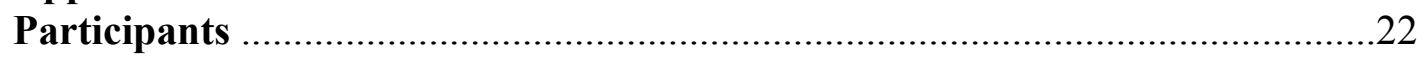

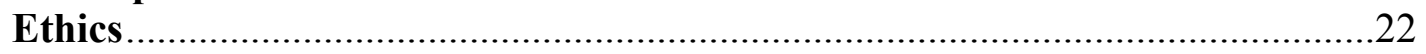

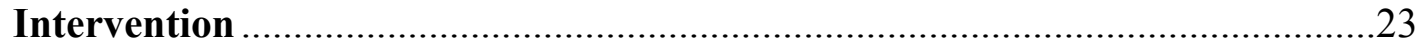

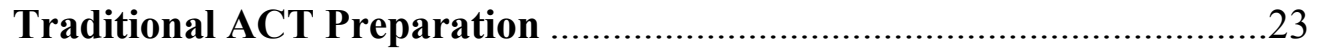

Teaching Critical Thinking Skills .......................................................24

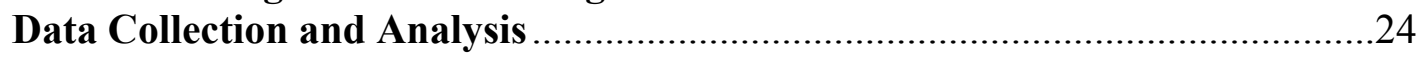

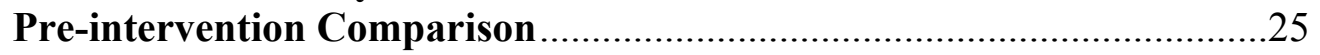

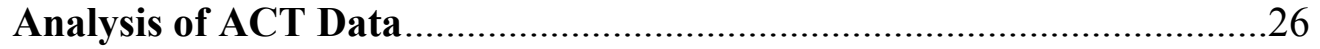

Analysis of Ennis-Weir Critical Thinking Essay Test ..........................22

Analysis of Pre-ACT and Post-ACT Self-Efficacy Questionnaires .........28

Analysis of Interview Responses ......................................................29

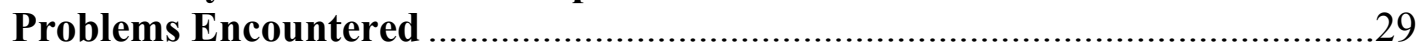

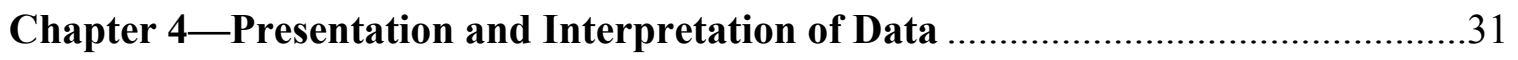

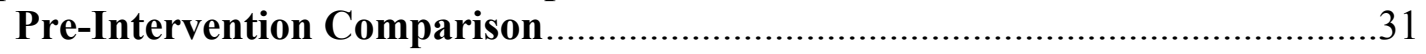

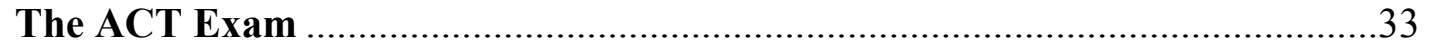

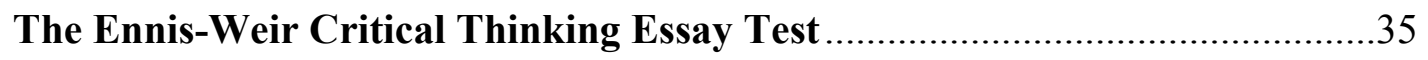

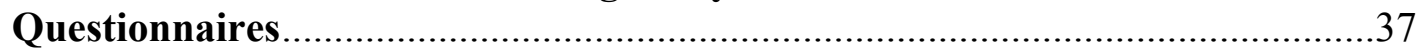

Questions Regarding Confidence Prior to the Intervention ....................37

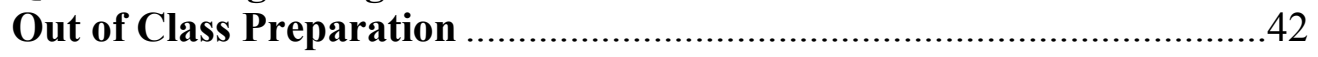




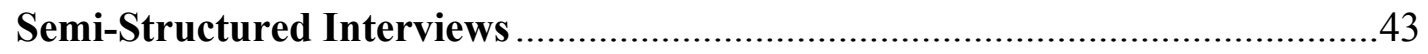

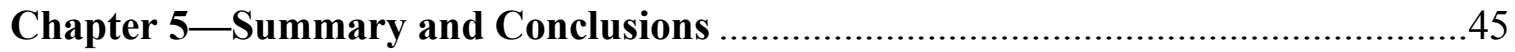

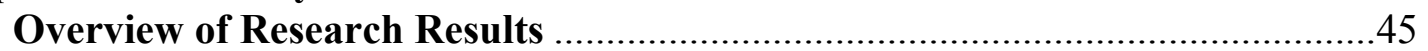

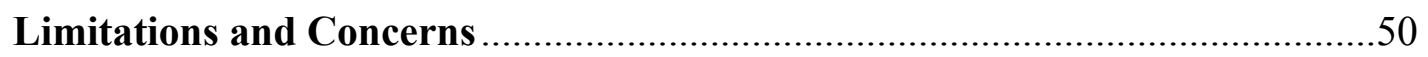

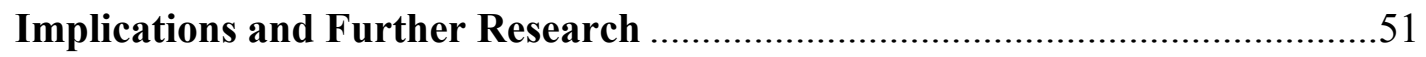

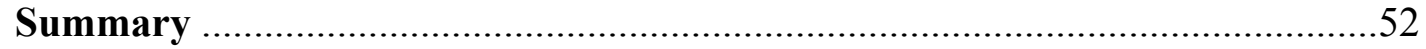

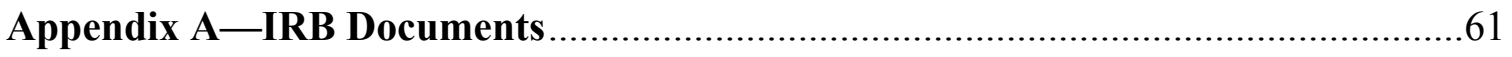

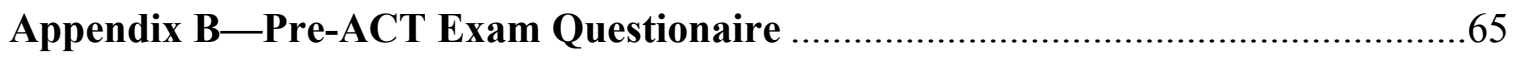

Appendix C_Post-ACT Exam Questionaire ........................................................67 


\section{List of Tables}

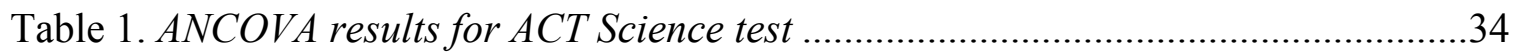

Table 2. ANCOVA results for Ennis-Weir Critical Thinking Essay Test..........................36

Table 3. Student responses to Statement 4: I feel I will score well on the ACT exam .......39

Table 4. Responses to Statement 3: I believe my ACT score will fall within

the following range .................................................................................40

Table 5. Responses to Statement 5: I feel that I scored well on the ACT exam ..................41 


\title{
Don't Get Testy About It: \\ Can Teaching Critical Thinking Skills Improve ACT Scores?
}

\begin{abstract}
Tests are an inevitable component of the educational process and the pressure, for teachers and students alike, can be tremendous. This study was designed to investigate and compare the effectiveness of two different strategies intended to assist students in the preparation for the ACT college entrance exam. One strategy was a continuation of the test preparation strategy that had been in place for several years and the other was a result of research about the type of thinking required to perform well on the ACT exam.

Students in the comparison group prepared for the ACT exam by reviewing the types of problems found on the ACT Science test and practicing them repeatedly. The experimental group was taught critical thinking skills through the implementation of activities based upon Toulmin's argument pattern. Students were pre/post tested on a practice ACT exam and on an essay test designed to measure critical thinking skills. Additionally, students completed a questionnaire designed to elicit confidence levels both before and after taking the ACT in order to determine whether using an untested preparation strategy would have a negative effect on student test scores.

While both groups showed gains on the ACT exam from the pre-test, neither group performed better than the other. Possible explanations for this result include loss of instructional time as a result of inclement weather and student apathy for the pre-test. Although students in the experimental group voiced concern and dismay with the
\end{abstract}


preparation strategy of learning critical thinking skills, it did not diminish self-reported confidence and did not appear to have a negative impact on the resulting ACT scores on the Science test. Ideas for making improvements in the study and for areas of future research are also discussed. 


\section{Acknowledgements}

No acknowledgment can ever convey the gratitude I have for my advisor, Dr.

Shari Stockero, without whom this project would never have been completed. Her comments and ideas were always thoughtful and much appreciated.

Likewise, my thanks and appreciation to friends and family who listened while I

thought aloud and were always there to throw much needed encouragement my way. 


\section{Chapter 1-Introduction}

The race to the mailbox to open the prized college acceptance letter is a longstanding ritual which, for many students, signals the beginning of the journey to personal success. That journey actually begins much earlier since most universities in the United States require a minimum score on an entrance exam, either the ACT or the SAT (Federal Student Aid, 2015). Even if a student does not plan to attend college, according to Governor Rick Snyder's website, all students in Michigan must take a college entrance exam. Until this year the exam has been the ACT, but the College Board's SAT exam will be administered beginning in 2016 (Snyder, 2015). Regardless of which test is used, almost a year before the jaunt to the mailbox to find out whether they have been accepted into the college they hoped for, many students experience stress and anxiety about the allimportant entrance exam.

While the individual student may be fraught with fear over the entrance exams, most school districts worry about these tests also. The resultant scores are public knowledge and may be accessed at the State of Michigan website, MI School Data (https://www.mischooldata.org/). Further, Michigan allows schools to adopt the schools of choice program (State School Aid Act of 1979), which has no doubt led to competition among districts for students. Consequently, the college entrance exam is a high stakes game for every school district as the quality of the education it provides is judged by student scores on this test. 
In many ways, students in my Environmental Science classroom mirror the general population of high school students in Michigan, with grade point averages in the range from 0.1 to more than 4.0. Just as many students in Michigan underperform on the Science portion of the ACT, mine do also. Based on empirical evidence, a College Readiness Benchmark score of 23 represents the minimum score a student should achieve to be considered college ready in Biology (ACT, Inc., n.d.). In 2013, the average science score in Michigan was 20.2 (ACT, Inc., n.d.); the average science score for students at my high school was 20.6 (MI School Data, n.d.). If the population in my classroom reflects the general population in Michigan, perhaps other teachers are struggling with the same issues that confront me.

In response to the increased pressure to raise test scores, our administration encourages teachers to (a) practice ACT exams repeatedly, (b) teach students how to recognize each type of question (data representation, research summaries, and conflicting viewpoints), and (c) provide specific strategies tailored to help answer each type of question. Additionally, some of my students put pressure on themselves to score well on the ACT because they dream of acceptance into a specific university. For others, that pressure comes from parents and their respective dreams. I am left to wonder if I am doing enough or if there are ways I can better prepare my students for this rigorous exam, which may help them realize their aspirations.

Generally, I wondered if different strategies would culminate in different results, especially since students seemed to chafe at taking numerous practice tests. If the ACT 
tests science reasoning skills, then perhaps it would be more advantageous to teach students how to think critically since reasoning skills are a subset of critical thinking (Beyer, 1985). Completely unsure as to which method would produce the desired result of higher test scores, I decided to divide my six Environmental Science classes into two groups based upon grade point averages, such that the two groups had nearly identical GPAs and then implemented the two strategies in a quasi-experimental design to compare the resulting ACT scores.

The experimental group participated in activities and learning opportunities designed to teach students how to think critically, while the comparison group prepared for the exam using common test preparation strategies such as identifying question types, reviewing how to answer those types of questions, and practicing retired exam questions.

Although this seemed a likely answer to my question, I was also concerned about student confidence in ACT preparation. Since most teachers in my school prepare students by providing multiple opportunities to practice with retired ACT exams, would a different strategy, one with which students may harbor doubts, cause a decline in scores? As a consequence of the anxiety I witness in my students in relation to the ACT, I collected qualitative data in the form of surveys and interviews to ascertain if test preparation that differed from the norm might have a deleterious effect on test results.

In summary, the focus of the study was to compare two strategies for preparing students on the Science Reasoning portion of the ACT and to determine if the success of these strategies is affected by student confidence in the strategy itself. I specifically designed the study to answer the following questions: 
1. What effects do various instructional strategies designed to improve critical thinking skills have on student scores for the Science Reasoning component of the ACT?

2. Does a change from the traditional, expected method of preparation for the ACT test have an effect on student confidence for the exam? 


\section{Chapter 2-Literature Review}

\section{What is Critical Thinking?}

Thinking critically is a skill that has become recognized as an essential element and outcome of education as business leaders demand graduates with this ability and as technological advances make information readily and rapidly accessible (Willingham, 2007; Abrami et al, 2008). Students can touch a phone screen to search the internet for "answers", and are bombarded daily by the media with messages about products, ideas, and theories, but it is apparent that many students lack the basic skills required to properly evaluate and interpret information.

Although there appears to be agreement that critical thinking skills should be taught, there may be a disconnect between what is desired and the reality teachers face. While most educators envision teaching and learning as more than students scanning a textbook to find answers to lower level questions, many students and their parents consider this an acceptable and expected pathway for learning (Newman, 1988). Further, some students are resistant to thinking deeply because it is not an easy task (Gelder, 2005; Willingham, 2008). However, even if teachers find it difficult to teach and students find it difficult to perform, critical thinking in the form of argumentation is an essential component of the Next Generation Science Standards (National Research Council, 2013) and the Common Core State Standards (National Governors Association \& Council of Chief State School Officers [NGA-CCSSO], 2010). 
Prior to teaching critical thinking, it is necessary to have a thorough understanding of its meaning (Kuhn, 1999). Critical thinking (CT) has been explored and defined in the realms of philosophy, psychology, and more recently, education (Lai, 2011), and so at first glance it appears that this should be a straightforward endeavor. However, definitions and descriptions are numerous and disagreements abound. To describe $\mathrm{CT}$, many authors include the steps or procedures involved or mention the necessary skills. For example, Lipman (1987) describes CT as "analyzing, judging, hypothesizing, explaining and many other cognitive activities" (p. 5). However, Bailin (2002) and Fascione (1990) argue that describing CT in such a way confuses the action of thinking critically with its component parts, reducing it to a series of steps, the execution of which may or may not actually require critical thinking. While that may be, CT is a complex concept so clarification of the concept may justify the recitation of necessary skills. Kuhn (1999) supports the claim that teaching CT requires a precise and thorough understanding of the associated skills.

Halpern (2007) argues that no matter which definition is proffered, most are dichotomous such that they include the skills necessary to think critically and the disposition or attitude to carry them out. Fascione (1990) developed a definition of CT in concert with a consensus of expert researchers as follows:

We understand critical thinking to be purposeful, self-regulatory judgment which results in interpretation, analysis, evaluation, and inference, as well as explanation of the evidential, conceptual, methodological, criteriological, or contextual 
considerations upon which that judgment is based. CT is essential as a tool of inquiry. As such, CT is a liberating force in education and a powerful resource in one's personal and civic life. While not synonymous with good thinking, CT is a pervasive and self-rectifying human phenomenon. The ideal critical thinker is habitually inquisitive, well-informed, trustful of reason, open-minded, flexible, fair-minded in evaluation, honest in facing personal biases, prudent in making judgments, willing to reconsider, clear about issues, orderly in complex matters, diligent in seeking relevant information, reasonable in the selection of criteria, focused in inquiry, and persistent in seeking results which are as precise as the subject and the circumstances of inquiry permit. Thus, educating good critical thinkers means working toward this ideal. (p. 3)

In agreement with Halpern, it would appear that this comprehensive definition can be divided between skills (interpretation, analysis, evaluation, inference, explanation) and certain habits of mind (inquisitiveness, trustful of reason, open-minded, flexible, fairminded, hone, prudent, willing, diligent, focused and persistent). Adding one additional component, Saadatia, Tarmizib, and Bayatc (2010) reduced CT to a simple equation:

$$
\text { Attitude }+ \text { Knowledge }+ \text { Thinking Skills }=\text { Intelligent Thinking }
$$

Attitude may be coached and knowledge taught, but thinking skills cannot be satisfactorily exercised without reflection. Many researchers agree that one significant aspect of CT is metacognition (Kuhn \& Dean, 2004) and some even identify CT as a metacognitive process (Hogan, Dwyer, Harney, Noone, \& Conway, 2015). 
Metacognition is the act of thinking about one's thinking (Lipman, 1987). The role of metacognition in CT was supported by the results of a study by $\mathrm{Ku}$ and Ho (2010) in which participants verbalized their thoughts while performing various critical thinking tasks. These researchers demonstrated that skilled thinkers not only recognized the need for a plan and executed it when solving problems, but also evaluated whether changes to the plan were necessary; these are all attributes of metacognition (Ku \& Ho, 2010).

\section{How is Critical Thinking Measured?}

Just as CT is challenging to define, measuring it is an equally formidable task. Ennis (1993) states that it is difficult to assess CT because of its complexity and the multitude of attributes that should be examined in order to accurately reflect an individual's critical thinking skills. He suggests that a good assessment will be based upon a well-defined definition of CT and that its purpose for administration will be thought out in advance so that the test actually provides data that is useful and relevant. According to Shim and Walczak (2012), the most common assessments of CT include the "California Critical Thinking Skills Test (Fascione, 1990), the Collegiate Assessment of Academic Proficiency (CAAP; ACT, 2000), and Watson-Glaser Critical Thinking Assessment (Watson \& Glasser, 1952)" (p. 18). For many public school teachers, the costs for these tests may be prohibitive. Although not as recently as the review above, Ennis (1993) provided a comprehensive list of tests, sorted them into tests that only cover one aspect of CT and those that cover more than one, and provided a short synopsis for each test. He lists The Ennis-Weir Critical Thinking Essay Test (1985) as 
one that tests more than one facet of CT. The Ennis-Weir Critical Thinking Essay Test, which was used in this study, evaluates many aspects of CT that are needed for argumentation. Specifically, the Ennis-Weir Critical Thinking Essay Test assesses a student's ability to recognize appropriate reasons, assumptions, and other possible explanations for problems, and the ability to avoid equivocation, irrelevance, and overgeneralizations, among other common errors in thinking.

\section{How is Critical Thinking Taught?}

Before exploring how CT may be taught, it is necessary to address whether CT actually can be taught. After reviewing cognitive research literature, Willingham (2008) concluded that CT cannot be taught because it is a skill that cannot be improved upon with practice. From this initial premise and a review of various studies, he concluded that critical thinking is not a skill, but that by teaching metacognitive strategies in context with domain knowledge, a teacher may increase the likelihood that CT will ensue. A more encouraging study conducted by Reid and Anderson (2012) with university students in a quasi-experimental design suggested that an increase in student scores in a business course resulted from critical thinking skills taught to the experimental group, providing evidence that CT may be a skill that is teachable.

Unfortunately, Shim and Walczak (2012) cite a dearth of K-12 classroom research to clarify which instructional methods are useful in teaching CT, and do not believe that research has answered the question of why some strategies may be more successful than others. Halpern and Marin (2011) observed that few empirical studies on CT have been 
conducted with high school students. The lack of research at the high school level has necessitated the inclusion of some college level studies in this review.

Gains in CT skills were observed in a study conducted by Marin and Halpern (2011), which compared classrooms in which the explicit instruction of CT skills was used against classrooms in which CT skills were imbedded in the instruction of content. Students in both classrooms displayed gains on critical thinking tests, although the explicit instruction group was more successful. Explicit instruction was based on a program using a four-part model developed by Halpern (1998):

(a) a dispositional or attitudinal component that consisted of modeling critical thinking and actively encouraging thoughtful responding; (b) instruction in and practice with critical thinking skills; (c) structured training activities designed to facilitate transfer across contexts, which was accomplished by deliberately noting how specific thinking skills apply with very different topics; and (d) a metacognitive component, which included having students discuss the process of thinking (p. 451).

Other strategies for improving CT were identified in a three-year study conducted by Miri, David and Uri (2007), which included the use of real-world examples, openended discussions, and implementing short inquiry experiments. As in the Halpern study, students in the experimental group in this study showed a higher improvement in CT skills in comparison to the control group, which was taught using traditional methods. Similarly, Shim and Walczak (2012) investigated the effect of instructional practices on 
CT of university students when they implemented a study involving 19 institutions and more than 7,500 students. Using the ACT and student self-reports to assess growth in CT, the data suggested that posing challenging questions, providing academic support with abstract ideas, and providing assignments in which students were required to analyze and integrate ideas caused an increase in CT skills. Lastly, the authors further suggested analyzing arguments as a way to use questioning in an effective manner. Questioning has also been found to encourage metacognition. Kuhn and Dean (2004) assert that teachers should present questions designed to elicit student reflection on classroom activities. Further, they direct teachers to pose questions such as "how do you know" and "what makes you say that" (p. 270) to increase the chances that students will internalize these prompts, thereby facilitating metacognition.

\section{Transferability and Critical Thinking}

Another area of contention over critical thinking is whether learning critical skills in one context will transfer or generalize to another. Willingham (2008) argued that the exercise of CT skills is strongly associated with specific content knowledge, making it very difficult to transfer those skills to another domain. He asserted that as information is encountered, cognitive processes interpret it narrowly based upon prior experience and knowledge, which interferes with the ability to see "deep structures" (p. 11). Mulnix (2012) attacked his reasoning on two fronts, claiming research shows that CT is not domain specific and that $\mathrm{CT}$ is, in fact, a skill. Mulnix, however, may have failed to consider that Willingham offered suggestions, albeit pessimistically tempered, about 
teaching for transfer. After Willingham's (2008) initial assertions, he delved more deeply into the problems associated with transfer as he discussed the need for repeated practice with problems that contain "deep structures" and suggested that to a limited extent, metacognitive strategies may help.

In the same vein, Halpern (1998) urged CT skills be taught in a manner that allows students to recognize when it may be useful in another context. "When criticalthinking skills are taught so that they transfer appropriately and spontaneously, students learn to actively focus on the structure of problems or arguments so the underlying characteristics become salient, instead of the domain-specific surface characteristics" ( $p$. 453).

A convincing longitudinal study conducted by Lehman and Nisbett (1990) explored whether thinking critically is domain specific and if transfer is possible. University students were contacted randomly, selected for the study on the basis of reported majors, administered an initial test of reasoning and then a similar reasoning test four years later. These reasoning tests were specifically written to include a set of test questions that were not domain specific and were posed in "either scientific or everydaylife contexts" (p. 955) to test for transferability of specific thinking skills. They found that those students with majors comprised of courses that taught statistical and methodological reasoning (social sciences and psychology) performed better than students in other majors on questions related to these types of reasoning. Similarly, students with majors that included courses teaching conditional reasoning (natural 
science and humanities) did better on questions related to conditional reasoning. They concluded that "reasoning can be taught and ... that different undergraduate disciplines teach different kinds of reasoning to different degrees" (p. 959).

\section{Argumentation as a Critical Thinking Skill}

The ability to argue effectively is recognized as a CT skill (Ennis, 1993) and as central to the scientific process (Chowning, Griswold, Kovarik, \& Collings, 2012). Perhaps for this reason, composing an argument is a key focus in the Common Core State Standards, which requires students in grades 11-12 to be able to "Write arguments focused on discipline-specific content." (NGA-CCSSO, 2010, p. 64) and as a Science and Engineering Practice in the Next Generation Science Standards (NGSS, 2013). Although the ability to write arguments may be valued by educators and employers, most students are not proficient at producing cogent arguments (Chowning, Griswold, Kovarik, \& Collins, 2012; Mulnix, 2010). Therefore they must be explicitly taught how to analyze, interpret, and formulate arguments (Simon, Erduran, \& Osborne, 2004).

Arguments may be constructed in writing (e.g., in an essay) or as discourse (e.g., in debate). In either form, many researchers utilize Toulmin's argument pattern for the basis of instruction. Toulmin (1958) outlined six components of a persuasive argument: claim, evidence, warrants, backing, qualifiers, and rebuttal, although some simplify this to the main elements of claim, data, warrant (Katchevich, Hofstein, \& Mamlok-Naaman, 2013; Osborne, Erduran, Simon, \& Monk, 2001). Using Toulmin's argument pattern 
provides a basis for determining the quality of an argument and a structure for an argument (Simon, Erduran, \& Osborne, 2006).

During the developmental phase of a long-term study on argumentation, Osborne, Erduran, Simon, and Monk (2001) argued that materials for teaching students how to argue effectively must contain certain elements and be taught using specific strategies. They asserted that problems presented to students should have more than one interpretation which will require them to compare and contrast; students should actively construct arguments using evidence; and students should determine the quality of arguments by examining the arguments of others. Proposed strategies included using small group interactions, using "writing frames" (p. 67) or sentence stems, and providing examples of strong and weak arguments. Cooperative learning in small groups has also been supported by the works of other researchers in the area of science and argumentation (Johnson \& Johnson, 1986; Tsay \& Brady, 2012; Zohar \& Nemet, 2002).

\section{Can Coaching Improve ACT Scores?}

The ACT college readiness assessment (ACT), developed in 1959 as a college admissions test and as an alternative to the SAT, assesses four content areas (English, Mathematics, Reading, and Science) using multiple choice questions and may include a writing test (ACT, Inc., 2015a). Students in Michigan take a college entrance examination as part of the required Michigan Merit Examination (Revised School Code, 1976). As mentioned earlier, in 2015 and prior years, Michigan utilized the ACT; beginning in 2016, it will administer the SAT (Snyder, 2015). 
ACT states on its website that it tests achievement in school curriculum, in contrast to the SAT which is "...more of an aptitude test, testing reasoning and verbal abilities" (ACT, Inc., 2015b) Interestingly, although the ACT website states that the SAT is a test of "reasoning", the description of the ACT Science test states that it "Measures the interpretation, analysis, evaluation, reasoning, and problem-solving skills required in the natural sciences" (ACT, Inc., 2015b). Exams that test reasoning ability "...are designed to measure general aptitude and skill," according to Montgomery and Lilly (2012). For that reason, this study considers the ACT Science reasoning subtest to be more appropriately labeled an aptitude test.

Whether as an aptitude test or an assessment of achievement, researchers have investigated the ability of entrance exams to predict institutional graduation rates and have found a correlation between ACT scores and completing college (Stumpf \& Stanley, 2002). Others connections have been researched, such as a study by Noble and Sawyer (2002) in which the predictive power of the ACT composite score for first-year college GPAs was investigated, concluding that the ACT was a better predictor than high school GPA. Additionally, Koenig, Frey, and Detterman (2008) have confirmed a correlation between the ACT and IQ scores.

These entrance exams play an important role in college admissions and student scores are often a deciding factor in granting scholarships (Montgomery \& Lilly, 2012). These are compelling reasons for parents and students to request test preparation or "coaching" in order to raise test scores and for schools to supply it. Coaching is the 
"systematic test preparation for a group of students that involves ... content review, item drill and practice, and an emphasis on specific test-taking and general test-wiseness" (Briggs, 2005, p. 89). Coaching may involve using books tailored to achieve higher test scores for a particular test, using a computer-based program, attending classroom-based instruction, or working with a tutor (Montgomery \& Lilly, 2012).

But whether it is possible to actually improve test scores through coaching continues to be debated (Montgomery \& Lilly, 2012). Designers of standardized aptitude and achievement tests assert that coaching does not improve test scores, while a metaanalysis conducted on randomized and quasi-randomized controlled trials concluded that coaching does "significantly improve treatment group scores over control group scores" (Montgomery \& Lilly, 2012, p. 8). Additionally, the question of effectiveness is clouded by a lack information about the nature of reported coaching interventions, making it difficult to determine what materials, strategies, and time are necessary to cause a gain in scores (Becker, 1990).

\section{Does Confidence Affect Student Achievement?}

This study also examined the possible effect that the nature of the intervention may have had on perceptions of self-efficacy in the experimental group and their resulting ACT scores. To appreciate the possible consequences of this effect, it is necessary to understand how students' perceptions affect learning. A model to explain the learning process was created by Biggs (1989) and consists of three elements: presage which consists of factors before learning begins and includes student characteristics and 
the learning environment, process which is how students approach learning (deeply or only on the surface), and product which is the learning outcomes. A study based upon the Biggs' model was conducted by Lizzio, Wilson, and Roland (2002), who randomly surveyed a large number university students to evaluate presage and academic achievement. They concluded that students' perceptions of the academic environment influence learning outcomes.

Another causal model used to explain the relationship between student perception and achievement was tested by Greene, Miller, Crowson, Duke, and Akey (2004). This model has two underlying beliefs: first, that "achievement is related to the cognitive strategies that students use to learn" (p. 463), and second, that "...the use of different types of strategies results in different learning outcomes, and, thus, different levels of achievement" (p. 463). These strategies can be divided into two groups, those that link new input with prior knowledge (i.e. meaningful or elaborative) and more shallow processes that generate a "less elaborate memory representation" (p. 463). Which strategy a student will choose, one that creates deeper more meaningful associations or one that relies upon rote processing, may in part be influenced by students' perception of instrumentality of the tasks they are asked to complete (Greene, et al., 2004; Miller \& Brickman, 2004). Surveying 220 high school student volunteers on such matters as classroom structures, degree of confidence, and student goals, which were then measured against achievement, Greene et al. (2004) concluded that perceived instrumentality of a classroom task had a direct effect on achievement outcomes. 
Just as student perceptions about perceived instrumentality of school tasks affect student achievement, so does self-efficacy. The Greene et al. (2004) study, for instance, determined that self-efficacy also plays a role in student choice of deep or shallow strategies, which contribute to student achievement. Likewise, Pajares (2003) contends that students' self-confidence is a critical factor in school achievement. He explains that self-confidence arises from the confluence of four factors: i) mastery experience which means that more success equals higher self-efficacy; ii) vicarious experience which may include social comparisons or peer modeling; iii) verbal information about competence; and iv) anxiety and stress. He opines that students who are confident will work harder, are more likely to persevere, and less likely to feel doubtful and uncertain.

\section{Summary}

Although it is difficult to define critical thinking simply, it has been described as a set of skills consciously employed for the purpose of solving problems. These skills may be measured using various tests developed for this purpose and care should be taken to make certain the test chosen actually measures the skill of interest. The Ennis-Weir Critical Thinking Essay Test, together with scoring information, is available online and measures skills associated with argumentation. This test was used in this study as a preand post-intervention measure of critical thinking since argumentation requires reasoning ability and the ACT Science Test measures Science reasoning skills.

Teaching critical thinking skills is another area of contention, however, those researchers who have seen positive results have concluded that explicit instruction is 
needed and that real-world examples should be employed in connection with collaborative learning, open-ended discussions, and short inquiry experiments. Additionally, teachers should hone their questioning techniques and instruct students on how to analyze arguments so that they may practice and improve their critical thinking skills. To accomplish this goal, Toulmin's argument pattern has been a foundation for many researchers studying argumentation. Regardless of the methods used to teach critical thinking skills, there remains the question of the efficacy of using coaching to raise standardized test scores. This study touches on all of these factors as the coaching interventions were implemented with the underlying current research in mind as students were instructed to work together to solve real-world problems and to identify and construct cogent arguments.

Other issues raised in the literature include transferability of CT skills and student self-efficacy. In order to be useful, critical thinking skills learned in one venue should transfer to other situations. While some researchers contend that these skills do not transfer, or do not transfer easily, a correlation between critical thinking skills and transferability has been documented. Another recognized relationship that may have affected the results in this study was student self-confidence. Researchers have determined that self-efficacy and students' beliefs do play a role in student achievement. These two areas, transferability and self-efficacy, were components of this research but the possible effects of transferability would have been limited to the experimental group; self-efficacy may have had an effect on both groups. In summary, if the transfer of 
critical thinking skills had occurred, a gain would have been expected in the experimental group as compared to the group that prepared with practice ACT tests. Student selfreported confidence, however, may have influenced student achievement in both groups. 


\section{Chapter 3-Methodology}

\section{Purpose of the Study}

There are a multitude of voices in the field of education, shouting from the sidelines, insisting that teachers try a new method or teaching strategy that will transform teaching and learning. Some may be research-based, others founded on a logical, seemingly brilliant idea that actually fizzles out upon implementation. As a classroom teacher, the scores my students receive on standardized tests such as the ACT or SAT may, for better or worse, become a measure of my ability to teach. It was imperative that I carefully and methodically explored strategies to improve tests scores because in more ways than one, their success is my success.

\section{Approach}

A quasi-experimental design was used to compare the effects of strategies for improving ACT scores and to provide insight into the factors that may influence test results. Data was collected using a retired ACT exam as a pre-test, which was compared against students' ACT scores for the Science portion of the exam (post-test). To analyze critical thinking skills, the Ennis-Weir Critical Thinking Essay Test was administered at the beginning and at the end of the intervention. Additionally, qualitative data was collected and analyzed regarding student confidence that may have had an effect on ACT scores. 


\section{Participants}

The study was conducted in six Environmental Science classes at a high school in the metropolitan Detroit area. Environmental Science is only available to students in the 11 th and 12th grades and is generally selected by students to fulfill Michigan's third science requirement. There were 49 students from the three classes in the experimental group and 53 students from the three classes that composed the comparison group. The two groups were created after calculating the average grade point average for each of the six classes and then assigning the classes into two groups such that there were no statistically significant differences in the average GPA for the two groups. The average GPA for the comparison group was 2.62; this group was composed of 25 females and 28 males $(\mathrm{N}=53)$. There were 24 females and 25 males in the experimental group $(\mathrm{N}=49)$ with an average GPA of 2.66.

\section{Ethics}

Prior to data collection, parental/guardian and student consent was procured for use of all student data included in this study (MTU approval M1273; see Appendix A for consent forms). Participants were assured that names would not be revealed and that they could withdraw from the study at any time.

The study was designed with the understanding that there is always an ethical concern when conducting a study using a quasi-experimental research design with students. The teacher-researcher must consider the possibility that one group will be short-changed or exploited as a result of receiving a less than effective intervention. To 
minimize this risk, the comparison group received the standard preparation generally advocated by my district while every element of the intervention provided to the experimental group was research-based and a logical strategy since the ACT test purports to test critical thinking skills.

\section{Intervention}

\section{Traditional ACT Preparation}

Students in the comparison group received the traditional ACT preparation that had been suggested to me upon my employment with the district. Instruction began with students taking the Science Reasoning portion of a practice ACT exam (ACT, Inc., 2005); the exam was scored using DataDirector (Riverside Publishing, version 4.35.3). The following day students looked at the practice test again and were supplied with the correct answers. Discussion ensued concerning the three question exam formats (Data Representation, Research Summaries, and Conflicting Viewpoints) and tips published by the Walton-Verona Independent Schools (ACT Science, n.d.) were used to outline strategies for approaching each type of question. A total of six days were dedicated to the intervention, including one day for the initial instruction and five additional days during which students engaged in timed practice sessions for the various types of question

formats. Students were reminded about the strategies as they practiced exam-taking skills. 


\section{Teaching Critical Thinking Skills}

Research-based strategies for teaching critical thinking skills were implemented using ideas and strategies from Teaching Argument Writing, Grades 6-12 (Hillocks, Jr., 2011). This book was chosen because the methods discussed most closely echo the prevalent theories and concepts advocated in argumentative research literature. For example, Hillocks (2011) suggests using "whodonit mysteries" (p. 15) for engagement, relies upon Toulmin's argument structure, and stresses collaborative learning techniques. Utilizing Hillocks' "Slip or Trip" (p. 16) to engage students in the analysis of evidence, the development of warrants, and the process of solving problems, students were introduced to Toulmin's argument pattern on the first day of the intervention. For five additional days thereafter, students analyzed another murder mystery, evaluated arguments, and practiced identifying and making claims and warrants.

\section{Data Collection and Analysis}

To compare the effectiveness of the two standardized test preparation strategies and to answer other questions related to this study, data were collected as follows:

(i) A pre-test using a retired version of the Science Reasoning portion of the ACT (version 59f; ACT, Inc., 2005) was given to students in both the comparison and experimental groups at the beginning of the second semester, with raw scores converted to an estimated ACT score;

(ii) The Ennis-Weir Critical Thinking Essay Test was administered to students in both groups, both as a pre-and post-test; 
(iii) ACT scores for students in both groups were collected when they became available in May;

(iv) A Likert-type Self-Efficacy Questionnaire to determine ACT exam readiness/selfconfidence level was administered prior to the pre-test as a base-line measure of self-efficacy (see Appendix B);

(v) A similar Self-Efficacy Questionnaire was provided to students just after they sat for the ACT exam in March (see Appendix C);

(vi) Following completion of the post-questionnaire, a stratified random sample of an equal number of students from both groups were interviewed using a semistructured design to provide a deeper level of understanding about individual thoughts on ACT preparation and confidence.

\section{Pre-intervention Comparison}

For the results to be meaningful, the two groups were first evaluated to see if they were equivalent prior to the intervention on the variables of grade point average and pretest ACT scores. An independent samples $t$ test was performed to compare the average grade point of students in the comparison group and the experimental group. This was followed by an independent samples $t$ test that compared the pre-ACT practice scores of both groups. Likewise, an independent samples $t$ test was also conducted to compare the variables of grade point average and the Critical Thinking Essay pre-test for the subset of students who completed both the pre- and post- CT Essay Test. 


\section{Analysis of ACT Data}

In order to determine if one method of instruction (practicing ACT questions versus learning critical thinking skills) resulted in a better outcome on ACT scores, the ACT data was analyzed to determine if a difference existed between the pre-test and posttest scores for the comparison and experimental groups. Data related only to students who had completed both the pre-test and the ACT were included in this analysis. For the pretest, students recorded their answers on a scoring sheet, which was scanned into DataDirector $^{\mathrm{TM}}$ (Riverside Publishing, version 4.35.3). These raw scores were then translated into scale scores that are predictive of students' ACT scores using "Table 1, Procedures Used to Obtain Scale Scores from Raw Scores for the ACT Practice Test" (p. 63). Individual pre-test scores were compiled for both the experimental group $(n=42)$ and the comparison group $(n=46)$ against students' respective ACT Science scores reported in May.

In order to assess the relationship between the scores of the two groups and to test the null hypothesis that the means of the two groups were equal after adjusting for pretest scores, a one-way analysis of covariance (ANCOVA) was conducted. The pre-test scores were a covariate and the ACT scores were the dependent variable in this analysis.

Last, in order to evaluate whether student growth had occurred during the intervention period, the comparison group means on the pre-test practice ACT and ACT Science exam scores were compared using a paired-samples $t$ test. Similarly, the experimental group means on the pre-test practice ACT and ACT Science exam scores were analyzed using the same statistical method. 


\section{Analysis of Ennis-Weir Critical Thinking Essay Test}

To measure critical thinking skills before and after the intervention, the EnnisWeir Critical Thinking Essay Test (Ennis \& Weir, 1985) was administered to students. Only students who had completed the pre-test and post-test were included in this analysis. The comparison group $(n=39)$ and the experimental group $(n=28)$ completed essays at the beginning and end of the intervention period. The essays were graded in accordance with the rubric and instructions included with the test manual. As much as possible, the instructor tried to grade the essays without bias. For example, when writing the essay, the instructions directed students to number each paragraph 1 through 9. Paragraph 1 of each essay was graded for all essays before paragraph 2 was graded. Further, the instructor tried, when possible, to refrain from looking at student names on the essays until it was time to enter the grades on the Criteria and Scoring Sheet for the Ennis-Weir (p. 14).

After the pre-test and post-test essays were graded, the relationship between the scores of the two groups was analyzed by testing the null hypothesis that the means of the two groups on the post-test were equal after adjusting for pretest scores using a one-way analysis of covariance (ANCOVA). The pre-test scores were a covariate and the post-test scores were the dependent variable in this analysis.

In order to evaluate whether student growth in critical thinking had occurred during the intervention period, the comparison group means on the pre-test Critical Thinking Essay and post-test Critical Thinking Essay were compared using a pairedsamples $t$ test. Similarly, the experimental group means on the pre-test Critical Thinking 
Essay and post-test Critical Thinking Essay were analyzed using the same statistical procedure.

\section{Analysis of Pre-ACT and Post-ACT Self-Efficacy Questionnaires}

All students completed a Self-Efficacy Questionnaire before the intervention began in February 2015 (Comparison group $n=53$; Experimental group $n=46$ ). The preACT questionnaire was designed to survey students on self-reported confidence prior to beginning the intervention. In March 2015, after ACT testing was complete, students were asked to complete the post-ACT Self-Efficacy Questionnaire. Only those students who had filled out the pre-ACT Self-Efficacy Questionnaire were surveyed. Students absent on the day of the post-survey had an opportunity to complete the questionnaire at a later date so that the student samples would be identical. Most of the questions were Likert-type with four possible responses (strongly agree, agree, disagree, strongly disagree), although one question on the pre-ACT Self-Efficacy Questionnaire asked students to predict their ACT score before taking the exam, while the post-ACT SelfEfficacy Questionnaire asked students to predict their ACT score after taking the exam. Both questionnaires asked students to choose from among five ranges of possible ACT scores (12-16, 17-21, 22-26, 27-31, and 32+).

The responses from each questionnaire were inputted by the instructor into a free demo version of Qualtrics ${ }^{\circledR}$ software. Since the data was ordinal in nature, it was analyzed using a nonparametric test, the Mann-Whitney $U$ test, as recommended by Allen and Seaman (2007). 
The responses to the questionnaires were grouped according to area of concern. For example, the statement concerning student self-predicted ACT scores and the statement I feel that I will score well on the ACT exam were analyzed together using descriptive statistics. Similarly, questions regarding test preparation were analyzed together. Student comments made on the back of the questionnaires were typed and compiled into two documents, one for the comparison group and one for the experimental group, so that commonalities could be detected.

\section{Analysis of Interview Responses}

A stratified random sample was taken from each of the three classes in the comparison and experimental groups. A student from each class was randomly selected by placing student names into two groups, one for grade point averages above 3.00 and one for grade point averages below 3.00 (on a 4.00 scale). Two names from each class were chosen which resulted in six interviews conducted with students in the comparison group and six interviews with students in the experimental group. Interview responses were typed into two documents, one for the comparison group and one for the experimental group and analyzed for patterns and recurring themes related to responses about confidence and feelings concerning the intervention.

\section{Problems Encountered}

After allowing for three planned closures in February, the instructor had planned for approximately 17 days from the beginning of the third quarter until students took the ACT exam the first week in March. However, during this time period the school district 
experienced six closures for inclement weather, which severely curtailed plans for more extensive interventions. Not only were six instructional days lost, but the remaining days were filled to capacity with curriculum concerns that could not be set aside and so the treatments for both groups were necessarily shortened. Furthermore, the timed requirements of the practice ACT exam and the Ennis-Weir Critical Thinking Essay Test made it impossible to test all of the students. Therefore, only students who completed all of the assessments were included in this study. 


\section{Chapter 4-Presentation and Interpretation of Data}

In order to answer the research questions, data from four sources were evaluated. First, a baseline assessment consisting of 40 questions from a retired ACT exam was provided to all students in both the comparison and experimental groups and was administered under conditions similar to standardized testing procedures (e.g. no talking, 35 minute time limit). These test results were compared to the ACT scores which were available in late May 2015. Second, a measurement of critical thinking skills was evaluated with the Ennis-Weir Critical Thinking Essay Test (1985). This critical thinking measure was administered to all students in both groups, both at the start and at the end of the intervention period. Third, students in both groups answered a questionnaire designed to determine their level of confidence and to investigate attitudes toward test preparation.

Students were surveyed both at the start and conclusion of the intervention period. Lastly, a stratified random sample of students was interviewed to clarify and investigate students' thoughts about their confidence and the interventions. Evaluation of the data and results for each of these measures are discussed in the following sections.

\section{Pre-Intervention Comparison}

To determine if the comparison $(n=46)$ and experimental $(n=42)$ groups were comparable at the start of the intervention, two separate independent $t$ tests were conducted to compare the means of these two groups for the variables of grade point average and pre-test ACT scores. The results of an independent samples $t$ test showed that the difference in the mean grade point average of the comparison group $(\mathrm{M}=$ 
$2.89235, \mathrm{SD}=0.59397)$ and the mean grade point average of the experimental group (M $=2.74857, \mathrm{SD}=0.72424)$, were not significant at the 0.05 level of significance $(\mathrm{t}=$ $1.0218, \mathrm{df}=86, \mathrm{p}=0.310)$. Additionally, the results of an independent samples $t$ test showed that the difference in the mean score for student performance on the ACT practice pre-test of the comparison group $(\mathrm{M}=17.83, \mathrm{SD}=4.20)$ and the mean score for student performance for the experimental group $(\mathrm{M}=16.67, \mathrm{SD}=4.29)$, was not significant at the 0.05 level of significance $(t=1.2797, d f=86, p=0.204)$. Since the null hypothesis, that the means were the same could not be rejected, it is presumed that the comparison group and experimental group were comparable before the intervention period commenced.

A similar test was conducted between the subset of students who completed the Critical Thinking Essay test in the comparison $(n=39)$ and the experimental $(n=28)$ groups to check that each group was comparable before the CT Essay was administered. Grade point averages and pre-test CT Essay scores were analyzed and the results of the independent samples $t$ test showed that the difference in the mean grade point average of the comparison group $(\mathrm{M}=2.98403, \mathrm{SD}=0.54047)$ and the mean grade point average of the experimental group $(\mathrm{M}=2.92611, \mathrm{SD}=0.61366)$, were not significant at the 0.05 level of significance $(t=1.4088, d f=65, p=0.684)$. Similarly, the results of an independent samples $t$ test showed that the difference in the mean score for student performance on the CT Essay pre-test of the comparison group $(\mathrm{M}=3.36, \mathrm{SD}=5.03)$ and the mean score for student performance for the experimental group $(\mathrm{M}=1.93, \mathrm{SD}=$ 
5.91), was not significant at the 0.05 level of significance $(t=1.0662, \mathrm{df}=65, \mathrm{p}=$ 0.2903). Since the null hypothesis, that the means were the same, could not be rejected it is presumed that the comparison group and experimental group were comparable before the intervention period commenced.

\section{The ACT Exam}

Satisfied that the two groups were equivalent, student achievement on the ACT exam before the intervention was measured using a practice exam published by ACT, Inc. (2005) for the 2005/2006 school year. Only students who had completed both the pre-test and the ACT were included in this analysis. Individual's scores were compiled for both the experimental group $(n=42)$ and the comparison group $(n=46)$ against their respective ACT Science scores reported in May. In order to assess the relationship between the scores of the two groups and to test the null hypothesis that the means of the two groups were equal after adjusting for pretest scores, a one-way analysis of covariance (ANCOVA) was conducted. The pre-test scores were a covariate and the ACT scores were the dependent variable in this analysis. The ANCOVA showed that the difference in scores for the experimental group versus comparison group, controlling for the pretest, was not significant at a 0.05 significance level $(\mathrm{p}=0.921$; see Table 1$)$. This implies that no significant difference existed between the mean scores of achievement on the ACT Science test for the two groups. 
Table 1

ANCOVA results for ACT Science test

\begin{tabular}{lccc}
\hline & Comparison & Experimental & Total \\
\hline Observed means & 20.9783 & 20.4048 & 20.7045 \\
Adjusted means & 20.7500 & 20.6600 & 20.7000 \\
\hline
\end{tabular}

That a significant difference did not exist between the mean scores of the two groups may be interpreted as a finding that neither intervention had more of an effect on student achievement than the other. One reason for this outcome may be the lack of time to fully implement the experimental group treatment as a consequence of the inclement weather that interfered with the study. It is possible that more time for practice of critical thinking skills may have enabled the experimental group to exceed the comparison group outcome. In the Lehman and Nisbett (1990) study, students were evaluated for changes in reasoning ability in "the first term of their 1st year of school and again in the second term of their 4th year of school" (pp. 954-955). Similarly, the intervention applied in the Duran and Sendag (2012) investigation lasted for a period of 18 months, while the gains witnessed in the Reid and Anderson (2011) research were implement during the entire college course time period. Given that the current intervention lasted for only a month and could not be implemented every day as planned, relatively little time was devoted toward either intervention. While time limitations may have been a factor in the result that neither group out-performed the other, it did not inform the instructor as to possible intra-group gains that may have been experienced. 
To determine whether gains were achieved in the ACT scores of either or both groups, a paired samples t-test was conducted separately for each group to compare scores on the practice ACT pre-test against scores received on the ACT Science Test. For the comparison group, there was a significant difference in the scores for the practice ACT pre-test $(M=17.826087, \mathrm{SD}=4.202139)$ and the ACT Science Test $(\mathrm{M}=20.978261$, $\mathrm{SD}=4.057855)$ at a $5 \%$ significance level $(\mathrm{t}(45)=4.884928, \mathrm{p}<0.001)$. Similarly, there was a significant difference in the experimental group scores for the practice ACT pretest $(\mathrm{M}=16.666667, \mathrm{SD}=4.292175)$ and the ACT Science Test $(\mathrm{M}=20.404762$, $\mathrm{SD}=3.914074) ; \mathrm{t}(41)=5.575233 . \mathrm{p}<0.001)$.

Recall that standardized test designers claim that the best preparation for an achievement test or aptitude test is doing well in high school courses and that coaching has little to no effect on achievement. Since both groups received coaching, it is possible that both methods were relatively equal in effect, which may explain the results of the paired samples t-test which found that both groups showed a statistically significant improvement in pre-test and ACT Science test scores.

\section{The Ennis-Weir Critical Thinking Essay Test}

Critical thinking skills were measured using The Ennis-Weir Critical Thinking Essay Test (CT Essay) (Ennis \& Weir, 1985). The comparison group $(n=39)$ and the experimental group $(n=28)$ completed essays at the beginning and end of the intervention period. In order to assess the relationship between the scores of the each group against the other and to test the null hypothesis that the means of the two groups 
were equal after adjusting for pretest scores, a one-way analysis of covariance

(ANCOVA) was conducted. The pre-test scores were a covariate and the post-test scores were the dependent variable in this analysis. The ANCOVA for the experimental group versus comparison group, controlling for the pre-test, was not significant at a 0.05 level $(\mathrm{p}=.921 ;$ see Table 2$)$.

Table 2

ANCOVA results for Ennis-Weir Critical Thinking Essay Test

\begin{tabular}{lccc}
\hline & Comparison & Experimental & Total \\
\hline Observed means & 4.6410 & 3.5357 & 4.1791 \\
Adjusted means & 4.1400 & 4.2300 & 4.1800 \\
\hline
\end{tabular}

To assess whether critical thinking skills improved in the experimental and comparison groups after the intervention, a paired samples t-test was conducted separately for each group to compare scores on the pre-test and post-test scores on the CT Essay. Results for the comparison group indicated no significant difference in the scores for the practice pre-test $(M=3.36, S D=5.03)$ and the post-test $(M=4.42, S D=5.64)$ at a 0.05 significance level $(\mathrm{t}(37)=1.7326, \mathrm{p}=0.092)$. Similarly, it was determined that no significant difference existed in the experimental group scores for the CT Essay pre-test $(\mathrm{M}=1.93, \mathrm{SD}=5.91)$ and the post-test $(\mathrm{M}=3.11, \mathrm{SD}=6.45, \mathrm{t}(26)=1.7683, \mathrm{p}=0.089)$. These results suggest that neither group experienced a statistically significant increase in CT skills, not even in the experimental group for which an increase in critical thinking skills were specifically the goal of the test-preparation intervention. 
In light of the reduced class time available for instruction in critical thinking, these results are not surprising. As Mulnix (2012) explains, CT may be taught and modeled, but just as athletes must practice their skills, so must students practice critical thinking because "nothing can replace repetitive practice" (p. 474). As mentioned previously, repetitive practice over an extended period of time was not a viable option for this study as a result of multiple school closures. Burbach, Matkin, and Fritz (2004) measured student critical thinking skills using The Watson-Glaser Critical Thinking Appraisal and determined that skills had increased over the 14-week period for the course in their study. Research suggests that time is an important element in teaching and learning CT skills.

\section{Questionnaires}

All students completed a questionnaire before the intervention began in February 2015, and a similar questionnaire after they had completed ACT testing in March 2015. Most of the questions were Likert-type with four possible responses (strongly agree, agree, disagree, strongly disagree), although one question on the pre-ACT exam questionnaire asked students to predict their ACT scores before taking the exam while the post-ACT exam questionnaire asked to predict their ACT after taking the exam.

\section{Questions Regarding Confidence Prior to the Intervention}

To determine confidence levels, student responses to statements on the questionnaire were analyzed. As previously discussed, perception of instrumentality or how useful students believe classroom tasks to be, was indicated as a factor in self- 
confidence (Greene, et al., 2004; Miller \& Brickman, 2004). The statements on the questionnaire that concerned student perception of the importance of test preparation were statements 4 and 6 (preparation will be useful) and statements 7 and 9 (preparation will not be useful). In both the comparison and experimental groups, $96 \%$ of students either agreed or strongly agreed with the statement $I$ believe that preparing for the ACT exam will help me achieve a higher score than if I do not prepare, while students in the comparison group (89\%) and experimental group (91\%) also agreed or strongly agreed that If we take practice ACT exams in my classes, then I will score higher on the actual exam.

Student answers to those belief statements tended to agree with their responses to the opposite statements on the questionnaire regarding preparation for the ACT. The majority of students in both groups responded to Statement 7, No amount of preparation will help me reach a higher score on the ACT, and Statement 9, Preparing for the ACT exam is a waste of time. I can do well without extra preparation in class, with disagree or strongly disagree $($ comparison group $=92 \%$; experimental group $=89 \%$ ). Therefore, if students believed that the preparation they received would influence their scores, then there was the possibility that students who perceived the preparation as inadequate might have experienced a lessening of confidence.

To directly consider self-confidence levels, students were asked to predict their scores by responding to the statement I believe my ACT score will fall within the following range (statement 3 ) by selecting a score range and to the statement I feel that I 
will score well on the ACT exam (statement 4) by choosing from one of four choices: strongly disagree, disagree, agree, strongly agree. The responses to statement 4 are indicated in Table 3 below. In both the comparison group (83\%) and experimental group (72\%), most students agreed or strongly agreed that they would do well on the exam. A Mann-Whitney U test was conducted to evaluate differences in the medians between the experimental and comparison groups as to their responses presented in Table 3 . The test was not significant $(\mathrm{p}=0.32218)$ and therefore the null hypothesis that the medians were the same cannot be rejected. This suggests that the two groups had similar levels of confidence at the beginning of the intervention period.

Table 3

Student responses to Statement 4: I feel I will score well on the ACT exam

\begin{tabular}{lccc}
\hline & Comparison & Experimental & Total \\
\hline Strongly disagree & $0(0 \%)$ & $1(2 \%)$ & 1 \\
Disagree & $9(17 \%)$ & $12(26 \%)$ & 21 \\
Agree & $40(75 \%)$ & $30(65 \%)$ & 70 \\
Strongly agree & $4(8 \%)$ & $3(7 \%)$ & 7 \\
\hline \multicolumn{1}{c}{ Total } & 53 & 46 & 99 \\
\hline
\end{tabular}

At the beginning of the intervention period and just prior to completing the preACT questionnaire, the instructor discussed with students the range of ACT scores in the third item and explained that they were to consider any score above 22 as an indicator of college-readiness for purposes of this study. Their responses to statement 3 are indicated in Table 4. Although student responses to this statement do not clearly provide evidence of strong self-confidence, more than half of the students in both the comparison group 
(57.6\%) and the experimental group (65.2\%) indicated that they believed they would achieve a college-ready score.

Table 4

Responses to Statement 3: I believe my ACT score will fall within the following range

\begin{tabular}{lccc}
\hline & Comparison & Experimental & Total \\
\hline $12-16$ & $4(8 \%)$ & $1(2 \%)$ & 5 \\
$17-21$ & $19(36 \%)$ & $15(33 \%)$ & 34 \\
$22-26$ & $22(42 \%)$ & $24(52 \%)$ & 46 \\
$27-31$ & $6(11 \%)$ & $4(9 \%)$ & 10 \\
$32+$ & $2(4 \%)$ & $2(4 \%)$ & 4 \\
\hline Total & $53(101 \% *)$ & $46(100 \%)$ & 99 \\
\hline \multicolumn{5}{c}{ *Does not add to $100 \%$ due to rounding. }
\end{tabular}

\section{Questions Regarding Confidence Post-intervention}

The same students who completed the pre-ACT exam questionnaire were asked to fill out the post-ACT exam questionnaire. This questionnaire asked students to rate their agreement to statements that were similar to those on the pre-ACT exam questionnaire. As in the initial survey, the majority of students in the comparison group (77.4\%) and the experimental group (82.6\%) felt they had performed well on the exam (by scoring 22 or higher) in the post-intervention questionnaire. A Mann-Whitney U test conducted to analyze the hypothesis that the medians of the responses of the two groups are the same indicated that the difference in responses was not significant at a 0.05 significance level $(p=0.689)$ and therefore the null hypothesis was not rejected. This implies that the two groups had comparable levels of confidence after completing the ACT exam, although the percentage of those who agreed or strongly agreed with statement 5, I feel that I scored well on the ACT exam, decreased in the comparison group from the pre-ACT 
exam to the post-ACT exam questionnaire (from $83 \%$ to $78 \%$ ) and increased in the experimental group (from $72 \%$ to $83 \%$ ) (see Tables 3 and 5).

Table 5

Responses to Statement 5: I feel that I scored well on the ACT exam

\begin{tabular}{lccc}
\hline & Comparison & Experimental & Total \\
\hline Strongly disagree & $2(4 \%)$ & $0(0 \%)$ & 1 \\
Disagree & $10(19 \%)$ & $8(17 \%)$ & 21 \\
Agree & $37(70 \%)$ & $35(76 \%)$ & 70 \\
Strongly agree & $4(8 \%)$ & $3(7 \%)$ & 7 \\
\hline \multicolumn{1}{c}{ Total } & $53(101 \% *)$ & $46(100 \%)$ & 99 \\
\hline
\end{tabular}

A Mann-Whitney U test was also employed to separately compare the medians between the pre-ACT questionnaire responses to statement 5, I feel that I scored well on the ACT exam, to the post-ACT responses made within each group to test the null hypothesis that the medians were the same before and after the intervention. The test for the comparison group indicated that the difference in medians was not significant $(\mathrm{p}=$ 0.603 ) and therefore the null hypothesis cannot be rejected. This suggests that the confidence level for the comparison group was not diminished between the beginning of the intervention and after the taking the ACT. Similarly, after analysis of the experimental group pre-ACT responses against their responses on the post-ACT questionnaire for statement 5, the Mann-Whitney $U$ test indicated that the test was not significant $(p=0.384)$ and the null hypothesis was not rejected. This implied that no increase or decrease in the confidence level of the experimental group existed for the time period in question. 


\section{Out of Class Preparation}

Although not an integral part of this study, the instructor was interested in determining if students had prepared for the ACT outside of class (e.g. purchased a book or attended a commercial preparation course). In the comparison group, responses indicated that 14 of the 53 students $(26 \%)$ had engaged in some type of preparation outside of class. Similarly, in the experimental group, 14 of the 46 students $(30 \%)$ responded that they had prepared for the ACT by using an additional resource. Since the questionnaires were anonymous, and the questions not specific enough, the instructor was not able to pursue this aspect further. It should be noted, however, that students did not mention any preparation they may have had when provided with an opportunity to do so on the ACT Self-Efficacy questionnaire.

\section{Student Written Feedback}

Both the pre- and post-intervention ACT Self-Efficacy questionnaire contained a free response section without topic restrictions so students could make candid comments. None of the students in either group wrote comments on the pre-intervention ACT SelfEfficacy questionnaire. Approximately $21 \%$ of students in the comparison group wrote comments on the post-intervention ACT Self-Efficacy questionnaire, which could be grouped as: those regarding the ACT test itself, those regarding ACT preparation, and miscellaneous comments. A slightly higher percentage of students in the experimental group (24\%) authored comments and those comments fell into the same groups as in the comparison group. No student in either the comparison or experimental group made a comment regarding self-confidence. 
Although a significantly statistical difference was not found between the confidence levels of the two groups, there were differences in the comments students made about preparation for the ACT. For example, only one student in the comparison group penned a negative comment about their preparation on the post-questionnaire, stating that "the practice tests in this class didnt correspond w/actual ACT. Was kind of a waste" [sic]. However, four of the five students in the experimental group who made comments on the post-questionnaire did so to complain about the strategies employed by this study: "I wish we would've took more practice tests rather than critical thinking exercises. I feel that it would've been more beneficial" [sic], and "The ACT prep worksheet did not help at all if we would of took the practice test I would of because the worksheet did had nothing to do with the ACT" [sic]. No students in the experimental group made a single positive comment about the preparation received in class, however, one student in the comparison group wrote "The in class practice tests helped me alot on the Science portion. Thank you!" [sic].

\section{Semi-Structured Interviews}

In the comparison group, student interviews conducted with a stratified random sample of students in each class consisting of three students with a GPA greater than 3.0 and three students with a GPA less than 3.0, revealed that students generally felt that the preparation for the ACT provided in class made them feel more confident about their results on the Science portion of the ACT. In the strata of three students with grade point averages greater than 3.0, all thought they had done well on the exam and predicted 
scores above 22. Students with grade point averages less than 3.0 definitely felt that taking practice exams had helped and one commented that she "would have been surprised by the graphs without the practice."

In the experimental group, students with GPAs greater than 3.0 voiced the most disapproval for the critical thinking intervention. One student felt it was "too simple" and another opined that "practice tests would have helped more than what we did". Only one of the three students thought s/he had performed well on the Science portion of the exam, although the results provided in May revealed that all three had received scores of 21 or above.

Surprisingly, students in the experimental group with GPAs less than 3.0 displayed more confidence in their achievement on the Science portion of the ACT, as all three claimed to have performed well. One student thought that argumentation had actually helped him write better on the essay portion of the ACT; however, when that question was posed to other students in the experimental group, none agreed. Comments about the intervention included that it "helped a little bit" while another student felt it was "too different from the ACT and not enough concrete help." Overall, students in the experimental group were not confident that the intervention had helped them achieve a higher score on the ACT Science reasoning portion of the exam. 


\section{Chapter 5-Summary and Conclusions Overview of Research Results}

Teachers face the unenviable task of preparing students for standardized exams, a task that is stressful for all involved. The research questions posed herein were intended to clarify which of two instructional strategies_-learning critical thinking skills or repeated practice answering ACT test questions - would prove more efficacious for preparing students for the ACT exam. The instructor did not construct a hypothesis as to which method would prevail because she did not know. Further, the study was designed to investigate what effect using a new or different test preparation strategy might have on student confidence regarding their preparation for the ACT test. Student confidence may be important because research suggests an association between it and student achievement (Greene, et al., 2004; Pajares, 2003).

Prior to the intervention, no significant statistical difference was found between the comparison group and experimental group on the factors of grade point average and performance on the pre-test of a practice ACT exam and the pre-test of the Critical Thinking Essay Test. This was important to establish so that any differences that might have been found could be more reliably attributed to one or both of the interventions and not to the higher cognitive abilities of one group over the other.

With a level playing field established, it was found that neither group achieved a higher average score on either the ACT Science exam or the Critical Thinking Essay Test following the intervention. There was a significant difference, however, between each 
group's pre-test practice ACT exam and their respective ACT Science test scores, with a marked increase from the beginning of the intervention period to the end. This result suggests several implications that may interest teachers preparing students for standardized tests. Since neither group outperformed the other on the ACT Science test, it suggests that neither intervention was effective, or alternatively, that both were equally effective. The latter proposition will be explored first.

Because both groups showed increases in their scores by approximately the same amount, then the experimental group intervention (learning critical thinking skills) must have been successful, at least to the same degree as using practice ACT tests to prepare students for the exam. However, research indicates that critical thinking is difficult (Gelder, 2005; Willingham, 2008), and that teaching it takes time (Burbach, Matkin, \& Fritz, 2004) and practice (Mulnix, 2012). As previously mentioned, the intervention period was cut short by inclement weather and while this affected both interventions, the comparison group intervention (learning about and practice with ACT Science questions) was easier to implement and the instructor had five years of experience with this strategy. Therefore, although both interventions appear to support students to some extent, it seems unlikely that the increase in the scores of both groups were a result of the intervention alone.

If it cannot be said that both interventions were successful in supporting the large gains that were documented, then other explanations for these gains must be explored. How did students achieve a statistically significant improvement in test scores over the 
initial pre-test practice ACT? The questionnaire results may provide some insight. Student responses on the questionnaire indicated that the majority of students $(96 \%$ in both groups) planned to continue their education after graduation. Additionally, the predominant response from students in both groups was agreement that preparation for the ACT exam would be, or was, helpful. From this, it is reasonable to conclude that these students understood the importance of the exam and were vested in preparing for it. However, no matter the extent of the effort made by the instructor to simulate the conditions of the exam, nothing is quite the same as actually sitting in a silent room with a real test in hand, the future hanging in the balance. It is not a stretch to presume that the quality of student motivation in the pre-test situation versus the real event was very different.

The inference that motivation was lacking in the pre-test is supported by data for the pre/post-test ACT exam. It is reasonable to accept the premise that there would be a substantial difference in scores between the pre-test and post-test if students did not take the ACT practice pre-test seriously. The data revealed that $50 \%$ of the students in the comparison group scored more than three points higher on the actual ACT exam than on the practice ACT pre-test. In the experimental group, just over 57\% improved three points or more on the ACT exam as compared to the practice ACT pre-test. This three point difference is more than would be expected, as Briggs (2001) noted that students who took the SAT test twice would, on average, increase scores by 60 points. Since the students in this study did not take the SAT exam, it was necessary to reference a 
concordance between the SAT and ACT which indicated that one point on the ACT is equivalent to 40 points on the SAT (ACT and SAT ${ }^{\circledR}$ Concordance Tables, 2009). Roughly, this implies that taking the ACT twice should raise the composite score by one and one-half points. The ACT Science test is only a portion of the composite score, and while this study did not utilize composite scores, the fact that at least half of the students in both groups showed a gain twice as high as would be expected on the ACT Science test suggests that it is reasonable to attribute the substantial gain to a less than stellar effort on the pre-test.

Student comments from the interviews also support the contention that students did not take the ACT practice pre-test seriously. An academically gifted student mentioned that she thought taking the pre-test "for a grade" in other courses made a difference in her performance in these other courses. In this class, the ACT practice science pre-test was only graded for participation because it measures reasoning ability, something that had not been specifically taught in the course. Another student also stated that he felt many students did not take the pre-test seriously because it was not graded for accuracy.

More evidence for the assertion that neither intervention was effective can be demonstrated by the outcome of the pre- and post-intervention Critical Thinking Essay Test, which was administered to both groups. When the pre-test scores of the comparison group were compared against the respective post-test score for each individual in that group, and when those same categories were evaluated for the experimental group, the 
results indicated that both groups failed to show a statistically significant improvement in scores after the intervention period. Additionally, the experimental group, which participated in critical thinking exercises, did not outperform the comparison group. Again, this finding indicates that it is unlikely that the critical thinking intervention was instrumental in the gains observed in the pre/post ACT test.

In addition to the proposal that lack of effort on the ACT practice pre-test was a factor in the increase in scores from the pre- to the post-ACT, it is also reasonable to presume that exposure to the ACT practice exam may have had a small effect on the results. As mentioned earlier, Briggs (2001), a researcher without ties to testing companies, analyzed NELS data (National Education Longitudinal Survey of 1988), and determined that simply taking a test more than once provides a slight increase in test scores. More importantly, his research concluded that coaching provided by commercial preparation courses causes less than a one-point increase in test scores. The interventions provided in this study were not as intensive as those provided by commercial preparation courses. Therefore, it is likely that since both groups were exposed to the ACT exam through the ACT practice pre-test, some of the increase in scores may also be attributed to this exposure and not from either intervention.

Briggs (2001) also referred to speculation that coaching may provide students with more self-confidence. As previously discussed, there is a link between student selfefficacy and academic achievement. The questionnaires indicated that students in the comparison group (83\%) and in the experimental group (72\%) agreed that they were 
confident at the beginning of the intervention period. Similarly, the comparison group (78\%) and the experimental group (83\%) agreed that they were confident about their performance after taking the ACT exam. Student interviews suggested that the experimental group believed that the critical thinking intervention was not effective; however, differences in confidence levels of the comparison and experimental groups were not statistically significant.

Last, it appears that lack of engagement in traditional preparation for the ACT exam by repeated practice of the exam questions did not have a negative effect on student self-reported self-confidence in the experimental group. Both groups had similar levels of reported self-confidence both before and after the ACT exam. While student comments and interviews revealed a lack of confidence in the intervention, it did not appear to reduce student self-confidence about their performance on the ACT test itself.

\section{Limitations and Concerns}

The critical thinking intervention was curtailed as a result of inclement weather and although this loss of class time did not impair the intervention for the comparison group to the same extent as it should have for the experimental group, it did reduce the amount of time students had to practice ACT problems. The results could have provided more insight had the interventions been implemented for a longer time period, particularly because teaching and learning critical thinking skills is a time-intensive venture. 
Another concern related to the weather's impact on the planned schedule was the timing of the post-test for the Critical Thinking Essay Test and the post-ACT SelfEfficacy questionnaire. Both were provided to students after they had taken the ACT exam. Students were tired and complained bitterly about the need to do any cognitive tasks after such an arduous event. The post-ACT Self-Efficacy questionnaire might have provided more insight into the confidence students felt about the interventions before taking the ACT, without the influence of actually sitting for the exam.

\section{Implications and Further Research}

These findings may suggest to those concerned with preparing students for standardized achievement tests that any intervention should be carried out over an extended period of time. Although neither intervention was found to be more effective than the other, it may be the case that a combination of the two interventions may be more effective than either alone. Thus, an intervention that includes student exposure to the format of standardized tests in combination with teaching critical thinking skills carried out over an extended period of time may be an area for future research.

Although students were surveyed about whether participation in out-of-class ACT preparation had occurred, further questions about the specific type of preparation would have been necessary to reach any conclusions about the effects of additional test preparation. Further research about the type and extent of that preparation may be beneficial to teachers in order to better measure the effectiveness of in-class preparation. 
Additionally, some students had suggested that a grade for accuracy would have been more effective in prompting motivation during the administration of the ACT practice pre-test. Comparable levels of motivation during the pre- and post-test may have been an important factor in determining the effectiveness of each intervention. For teachers who resist the idea of assigning a grade for the pre-test, further research could investigate the usefulness of providing an incentive for students in the form of a reduction in homework or an option to drop the grade of one assignment to elicit an increase in student effort.

\section{Summary}

This study was conducted to answer two questions:

1. What effects do various instructional strategies designed to improve critical thinking skills have on student scores for the Science Reasoning component of the ACT?

2. Does a change from the traditional, expected method of preparation for the ACT test have an effect on student confidence for the exam?

Students were prepared for the ACT exam using two different strategies. Argumentation was the vehicle for teaching critical thinking skills to students in the experimental group, while students in the comparison group were drilled repeatedly on questions taken from retired/practice ACT exams. The results showed that no difference existed in the mean scores of the two groups on the ACT Science exam; however, students in both groups realized a substantial gain in scores from their individual ACT 
practice pre-test and their respective ACT Science test scores. These gains may reasonably be attributed, however, to a lack of motivation during the pre-test as compared to the effort applied during the actual test situation. It may also be the case that more time would have been required to observe an effect from teaching critical thinking skills.

Although students in the experimental group were critical of the intervention, which involved learning critical thinking skills through argumentation, no difference was observed in their self-confidence as compared to the confidence reported by the comparison group after taking the ACT. Since both groups performed equally on the ACT exam, it suggests that this method of preparation did not have a negative effect on the outcome for students. In short, both interventions in this study produced similar results in terms of students' ACT Science test performance. 


\section{References}

Abrami, P. C., Bernard, R. M., Borokhovski, E., Wade, A., Surkes, M. A., Tamim, R., \& Zhang, D. (2008). Instructional interventions affecting critical thinking skills and dispositions: A stage 1 meta-analysis. Review of Educational Research, 78(4), 1102-1134.

ACT, Inc. (2005). Preparing for the ACT, 2005-2006. Retrieved from http://www.satprepforadhd.com/PDFs/ACT\%20Practice\%20Test\%2059F.pdf.

ACT, Inc. (2015a). Description of the ACT. Retrieved from http://www.actstudent.org/testprep/descriptions/.

ACT, Inc. (2015b). Frequently asked questions: What is the difference between the ACT and SAT?. Retrieved from http://www.actstudent.org/faq/actsat.html.

ACT and SAT ${ }^{\circledR}$ Concordance Tables. (2009). College Board. Retrieved July 3, 2015, from http://research.collegeboard.org/sites/default/files/publications /2012/7/researchnote-2009-40-act-sat-concordance-tables.pdf.

ACT Science (n.d.). Walton-Verona Independent Schools. Retrieved from http://wv.kyschools.us/students/highschool/science/Documents/ACT/ACT\%20Sci ence\%20review\%20tips.pdf.

Allen, E. \& Seaman, C. A. (2007). Likert scales and data analyses. Retrieved from http://asq.org/quality-progress/2007/07/statistics/likert-scales-and-dataanalyses.html. 
Bailin, S. (2002). Critical thinking and science education. Science \& Education, 11(4), 361-375.

Becker, B. J. (1990). Coaching for the Scholastic Aptitude Test: Further synthesis and appraisal. Review of Educational Research, 60(3), 373-417.

Beyer, B. K. (1985). Critical thinking: What is it. Social education, 49(4), 270-276.

Biggs, J. B. (1989). Approaches to the enhancement of tertiary teaching. Higher education research and development, 8(1), 7-25.

Briggs, D. C. (2005). Meta-analysis: a case study. Evaluation Review, 29(2), 87-12.

Burbach, M. E., Matkin, G. S., \& Fritz, S. M. (2004). Teaching critical thinking in an introductory leadership course utilizing active learning strategies: A confirmatory study. College Student Journal, 38(3), 482.

Chowning, J. T., Griswold, J. C., Kovarik, D. N., \& Collins, L. J. (2012). Fostering critical thinking, reasoning, and argumentation skills through bioethics education. PloS one, 7(5), e36791. doi:10.1371/journal.pone.003679.

Ennis, R. H. \& Weir, E. (1985). The Ennis-Weir critical thinking essay test. Retrieved from http://faculty.education.illinois.edu/rhennis/tewctet/Ennis-Weir_Merged.pdf

Ennis, R. H. (1993). Critical thinking assessment. Theory into Practice, 32(3), 179-186

Facione, P. A. (1990). Critical thinking: A statement of expert consensus for purposes of educational assessment and instruction. Millbrae, CA: The California Academic Press. 
Governor Rick Snyder Reinventing Michigan. (2015, June). Frequently asked questions on Michigan's switch from the ACT to the SAT. Retrieved from http://michigan.gov/snyder/0,4668,7-277-57577_60279-344790--,00.html.

Halpern, D. F. (1998). Teaching critical thinking for transfer across domains: Disposition, skills, structure training, and metacognitive monitoring. American Psychologist, 53(4), 449.

Halpern, D. F. (2007). The nature and nurture of critical thinking. Critical Thinking in Psychology, 1-14.

Hillocks, G. (2011). Whodunit? In L. Luedeke (Ed.), Teaching argument writing, grades 6-12: Supporting claims with relevant evidence and clear reasoning. Portsmouth, NH: Heinemann.

Hogan, M. J., Dwyer, C. P., Harney, O. M., Noone, C., \& Conway, R. J. (2015). Metacognitive skill development and applied systems science: A framework of metacognitive skills, self-regulatory functions and real-world applications. In A. Peña-Ayala (Ed.), Metacognition: Fundaments, Applications, and Trends (pp. 75106). Cham, Switzerland: Springer International Publishing.

Johnson, R. T., \& Johnson, D. W. (1986). Cooperative learning in the science classroom. Science and Children, 24, 31-32.

Katchevich, D., Hofstein, A., \& Mamlok-Naaman, R. (2013). Argumentation in the chemistry laboratory: Inquiry and confirmatory experiments. Research in Science Education, 43(1), 317-345. 
Koenig, K. A., Frey, M. C., \& Detterman, D. K. (2008). ACT and general cognitive ability. Intelligence, 36(2), 153-160.

Ku, K. Y., \& Ho, I. T. (2010). Metacognitive strategies that enhance critical thinking. Metacognition and Learning, 5(3), 251-267.

Kuhn, D., \& Dean, Jr., D. (2004). Metacognition: A bridge between cognitive psychology and educational practice. Theory into Practice, 43(4), 268-273.

Kuhn, D. (1999). A developmental model of critical thinking. Educational Researcher, $28(2), 16-46$.

Lai, E. R. (2011). Critical thinking: A literature review. Pearson's Research Reports, 6, 40-41.

Lipman, M. (1987). Critical thinking: What can it be? Analytic Teaching, 8(1), 5-12.

Lizzio, A., Wilson, K., \& Simons, R. (2002). University students' perceptions of the learning environment and academic outcomes: implications for theory and practice. Studies in Higher Education, 27(1), 27-52.

MI School Data (n.d.). Retrieved from https://www.mischooldata.org/ DistrictSchoolProfiles/AssessmentResults/Act/ActCollegeReadiness.aspx.

Miller, R. B., \& Brickman, S. J. (2004). A model of future-oriented motivation and selfregulation. Educational Psychology Review, 16(1), 9-33.

Miri, B., David, B. C., \& Uri, Z. (2007). Purposely teaching for the promotion of higherorder thinking skills: A case of critical thinking. Research in Science Education, $37(4), 353-369$. 
Mulnix, J. W. (2012). Thinking critically about critical thinking. Educational Philosophy and Theory, 44(5), 464-479.

National Governors Association Center for Best Practices \& Council of Chief State School Officers. (2010). Common Core State Standards for English language arts and literacy in history/social studies, science, and technical subjects. Washington, DC: Authors. Retrieved from http://www.corestandards.org/assets/CCSSI_ELA\%20Standards.pdf.

National Research Council (2013). Next Generation Science Standards. Retrieved from http://www.nextgenscience.org/sites/ngss/files/Appendix\%20F\%20\%20Science\% 20and $\% 20$ Engineering $\% 20$ Practices $\% 20$ in $\% 20$ the $\% 20$ NGSS $\% 20$ \%20FINAL\%20060513.pdf.

Osborne, J., Erduran, S., Simon, S., \& Monk, M. (2001). Enhancing the quality of argument in school science. School Science Review, 82, 63-70.

Osborne, J., Erduran, S., \& Simon, S. (2004). Enhancing the quality of argumentation in school science. Journal of Research in Science Teaching, 41(10), 994-1020.

Pajares, F. (2003). Self-efficacy beliefs, motivation, and achievement in writing: A review of the literature. Reading \& Writing Quarterly, 19(2), 139-158.

Qualtrics (2015). Qualtrics survey software [software]. Available from http://www.qualtrics.com.

Reid, J., \& Anderson, P. (2012). Critical thinking: The foundation of education in a technological world. Education in a Technological World: Communicating Current and Emerging Research and Technological Efforts, 1, 120-126. 
Revised School Code of 1976, Act 451, Mich. Comp. Laws § 380.1279g, Amended 2008. Retrieved from http://www.legislature.mi.gov/ \%28S\%28euhoxpjyiaoao01xn4axlc3h\%29\%29/mileg.aspx?page=getObject\&obje $\mathrm{ctName}=\mathrm{mcl}-380-1279 \mathrm{~g}$.

Riverside Publishing (2011). DataDirector [computer software]. Available from http://riversidepublishing.com/products/DataDirector/index.html.

Saadati, F., Tarmizi, R. A., \& Bayat, S. (2010). Assessing critical thinking of postgraduate students. Procedia-Social and Behavioral Sciences, 8, 543-548.

Shim, W. J., \& Walczak, K. (2012). The impact of faculty teaching practices on the development of students' critical thinking skills. International Journal of Teaching and Learning in Higher Education, 24(1), 16-30.

Simon, S., Erduran, S., \& Osborne, J. (2006). Learning to teach argumentation: Research and development in the science classroom. International Journal of Science Education, 28(2-3), 235-260.

State School Aid Act of 1979, MCL 388.1705 and 388.1705c, $\S \S 105$ or 105c, as amended.

Student Federal Aid. (2015, June). If you're applying to college or graduate school, you may need to take certain tests. Retrieved from US Department of Education website https://studentaid.ed.gov/sa/prepare-for-college/tests.

Stumpf, H., \& Stanley, J. C. (2002). Group data on high school grade point averages and scores on academic aptitude tests as predictors of institutional graduation rates. Educational and Psychological Measurement, 62(6), 1042-1052. 
Toulmin, S. (1958). The uses of argument. Cambridge: Cambridge University Press.

Tsay, M., \& Brady, M. (2012). A case study of cooperative learning and communication pedagogy: Does working in teams make a difference? Journal of the Scholarship of Teaching and Learning, 10(2), 78-89.

Willingham, D. T. (2008). Critical thinking. American Educator, 31(2), 8-19.

Zohar, A., \& Nemet, F. (2002). Fostering students' knowledge and argumentation skills through dilemmas in human genetics. Journal of Research in Science Teaching, $39(1), 35-62$. 


\section{Appendix A-IRB Documents}

\section{Parent Consent Letter}

Dear Parent/Guardian,

Your son or daughter is a student in my Environmental Science class. As a graduate student at Michigan Technological University, I am conducting a research study that is intended to help me make better decisions about the education your student receives in my classroom.

The project concerns an investigation into the best way to prepare students for the ACT exam. Students in three of my six Environmental Science classes will be taught specific critical thinking skills while students in the other three Environmental Science classes will prepare for the ACT by practicing with retired exams, a method that has been used for several years. Regardless of which class your student is in, any student who wishes to practice taking the ACT will still have the opportunity to the take practice ACT exam offered by Anchor Bay High School in February. In order to determine the effect that the two methods have on ACT exam performance, I am asking permission to analyze your student's responses to tests and surveys given both before and after ACT preparation instruction, and his or her scores on the Science Reasoning portion of the ACT. The project is designed to benefit students at Anchor Bay High School so that we may optimize ACT test results for our students.

There are several things you should know:

1. Participation in this research project is voluntary. No student will be punished nor rewarded for the decision he or she makes about participation.

2. Even if permission has been granted, at any time during this project you or your student may withdraw permission to participate without penalty of any kind.

3. If your student agrees to participate, no names nor identifying characteristics of any kind will be used in this project. I will assign numbers to all students participating in this study; during the duration of the study, I will keep the key linking names to those numbers in a locked drawer at school. No one else will have access.

4. If your student does not agree to participate, the data from the ACT test, preand post-tests, surveys, and/or interviews will not be used in my project. Your student will still be required to participate in all class activities.

5. Permission to participate means that your student may be invited to answer several interview question at the end of this project. Your student may decide at any time 
to withdraw permission without penalty and is not required to answer the interview questions if selected.

6. All students returning this letter signed by a parent will receive extra credit whether or not you have agreed to allow your student to participate.

7. Federal regulations require that I maintain my research data for three years after the study is closed. All data will be stored in a secure, locked location and will be shredded upon expiration of the three year period. Any documentation that links your student's name to specific data will be destroyed on or before June 30, 2015.

The Michigan Tech Institutional Review Board has reviewed my request to conduct this project. If you have any concerns about your rights in this study, please contact the Office of Compliance, Integrity, and Safety at 906-487-2902 or email IRB@mtu.edu. Please feel free to call me after school or email me at any time if you have any questions.

Very truly yours,

Glenda L. LaBruyere, Environmental Science

(phone)

(email)

Please tear off this bottom portion, sign, and have your son/daughter return it to me. Retain the top portion for your records.

Student name (please print):

My son/daughter has my permission to participate in this research project.

My son/daughter does not have my permission to participate in this research project.

Parent/Guardian Signature: 


\title{
STUDENT ASSENT TO PARTICIPATE IN RESEARCH
}

\author{
Study to Compare ACT Preparation Strategies
}

1. My name is Ms. LaBruyere and in addition to being your teacher, I am also a student at Michigan Technological University.

2. I am asking you to take part in a research study because I am trying to learn more about how best to prepare students for the ACT.

3. If you agree to be in this study, I will ask you to do a few things over the next few weeks.

- I may ask you questions about how you feel about the learning strategies.

- I will give you surveys about how confident you feel about taking the ACT.

- I will give you tests that may estimate your score on the ACT.

- I will access your actual ACT score.

4. I do not believe that you will be hurt or upset by being in this study. If you take part in the study and believe that you have been hurt or upset in any way, you may stop being in the study at any time. I will not tell anyone else the things you tell me about the ACT preparation strategies or anything you tell me about yourself or any other person.

5. This study will probably help you be better prepared for the ACT, but if you participate in this study, it will teach me important ways to help other students like you in the future. Your name will not be included in my study and no one, other than me, will know how you performed on any of these tests unless you decide to share that information. All of your work will be stored in a locked location. Any documents that link your name to specific data will be destroyed by June 30, 2015. Any remaining papers will be destroyed three years after I finish this research.

6. Please talk this over with your parents before you decide whether or not to participate. Your parent must also give permission for you to take part in this study. Even if your parent says "yes," you can still decide not to do this.

7. If you don't want to be in this study, you don't have to participate. Remember, being in this study is up to you and no one will be upset if you don't want to participate or even if you change your mind later and want to stop. If you choose not to participate in the study you will be expected to complete the assignments, but not participating will not affect the grades you receive.

8. You can ask any questions that you have about the study. If you have a question later that you didn't think of now, you can email me at (email) or ask me before, during, or after class. You may contact me at any time to ask questions about the study. 
9. Signing your name at the bottom means that you agree to be in this study. If you do not want to participate, you should not sign the form. You will be given a copy of this form after you have signed it.

Signature of Subject

Printed Name of Subject

Date 


\section{Appendix B-Pre-ACT Exam Questionaire}

\section{Pre-ACT Exam Questionnaire}

Students, your responses to these questions are anonymous and confidential. They will not be used for any purpose other than as data in the research paper I will write. The data is only as good as your willingness to respond with complete candor and thoughtfulness! Thank you in advance for helping me.
1. I have Environmental Science:
$\square$ 1st $\square$ 2nd
$\square 3 \mathrm{rd}$
$\square$ 4th
$\square$ 5th
6th

2. Gender: $\quad \square$ Female $\square$ Male

Environmental Science Teacher 1st Semester: $\square$ Mr. L $\square$ Ms. B

3. I believe my ACT score will fall within the following range: $\square 12-16 \square 17-21 \square 22-26$

$\square 27-31 \square 32+$

Please read carefully and only mark one answer for the following questions:

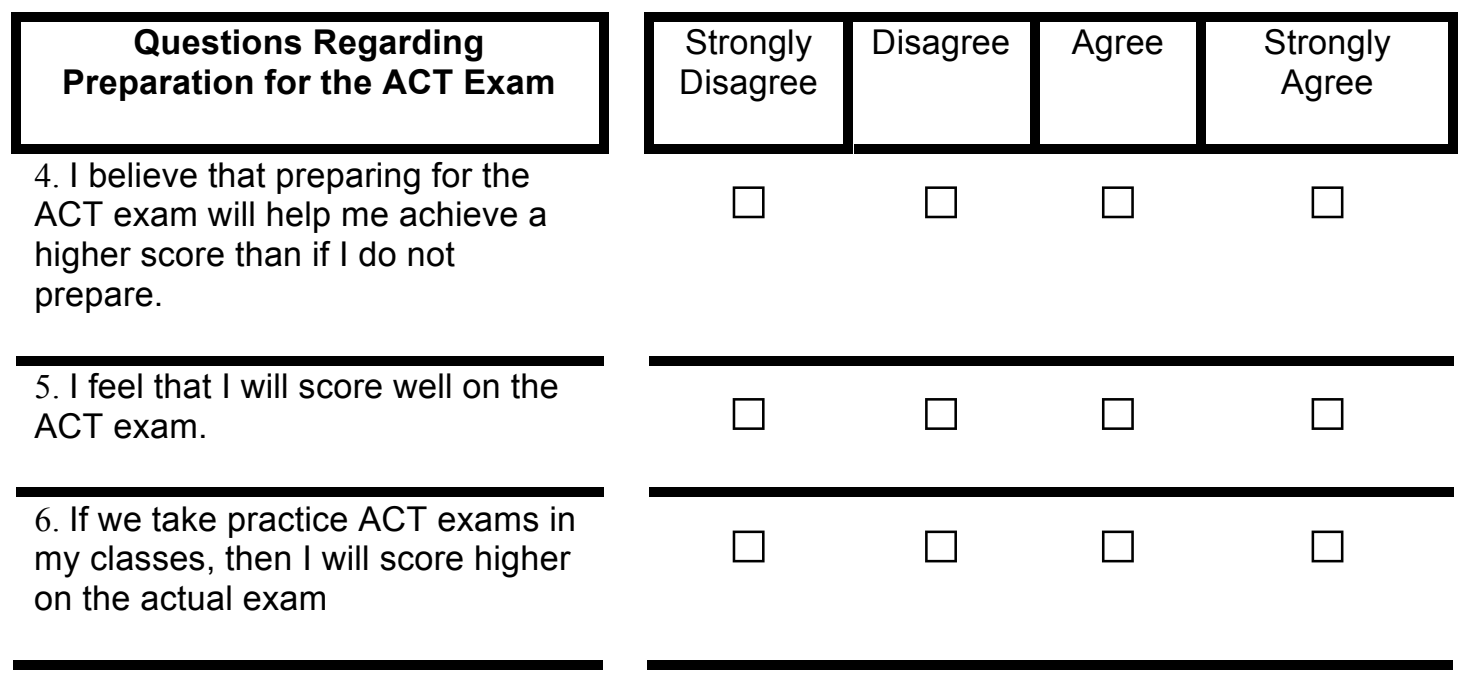




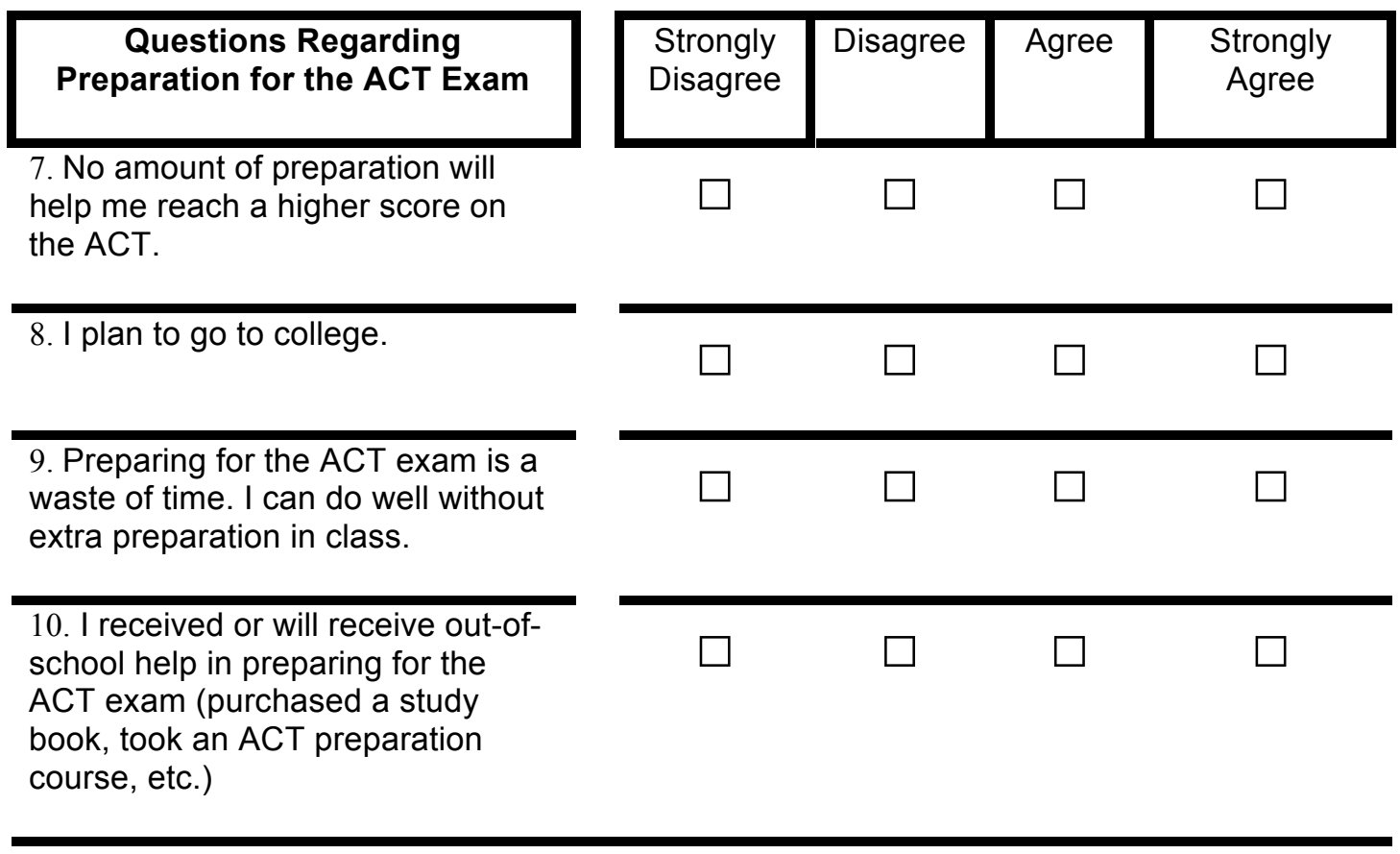

If you would like to make comments, please print them on the back but do not sign your name as I do not want to be able to identify you!

Comments: 


\section{Appendix C-Post-ACT Exam Questionaire}

\section{Post-ACT Exam Questionnaire}

Students, your responses to these questions are anonymous and confidential. They will not be used for any purpose other than as data in the research paper I will write. The data is only as good as your willingness to respond with complete candor and thoughtfulness! Thank you in advance for helping me.

\section{I have Environmental Science: $\quad \square 1^{\text {st }} \square$ 2nd $\square$ 3rd $\square$ 4th $\square$ 5th $\square$ 6th}

2. Gender: $\quad \square$ Female $\square$ Male
Environmental Science Teacher 1st Semester:
$\square \mathrm{Mr} . \mathrm{L}$
Ms. B

3. I believe my ACT score fell within the following range: $\square 12-16 \quad \square 17-21 \quad \square 22-26$

$\square 27-31 \quad \square 32+$

Please read carefully and only mark one answer for the following questions:

Questions Regarding
Preparation for the ACT
Exam

4. I believe that preparing for the ACT exam helped me achieve a higher score than if I did not prepare.

5. I feel that I scored well on the ACT exam.

6. Taking practice ACT exams in my classes helped me to score higher on the

\begin{tabular}{|l|l|l|l|}
\hline $\begin{array}{l}\text { Strongly } \\
\text { Disagree }\end{array}$ & Disagree & Agree & Strongly Agree \\
& & & \\
\hline
\end{tabular}

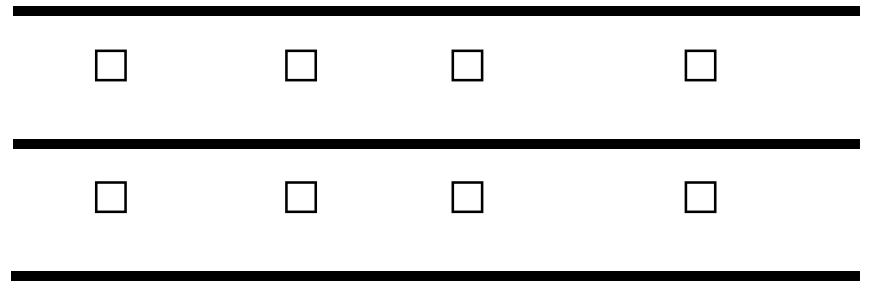

67 


Questions Regarding
Preparation for the ACT
Exam

actual exam.

7. No amount of preparation could have helped me reach a higher score on the ACT.

8. I plan to go to college.

9. Preparing for the ACT

exam was a waste of time. I

would have done well

without extra preparation in

class.

10. I received out-of-school

help in preparing for the

ACT exam (purchased a

study book, took an ACT

preparation course, etc.)
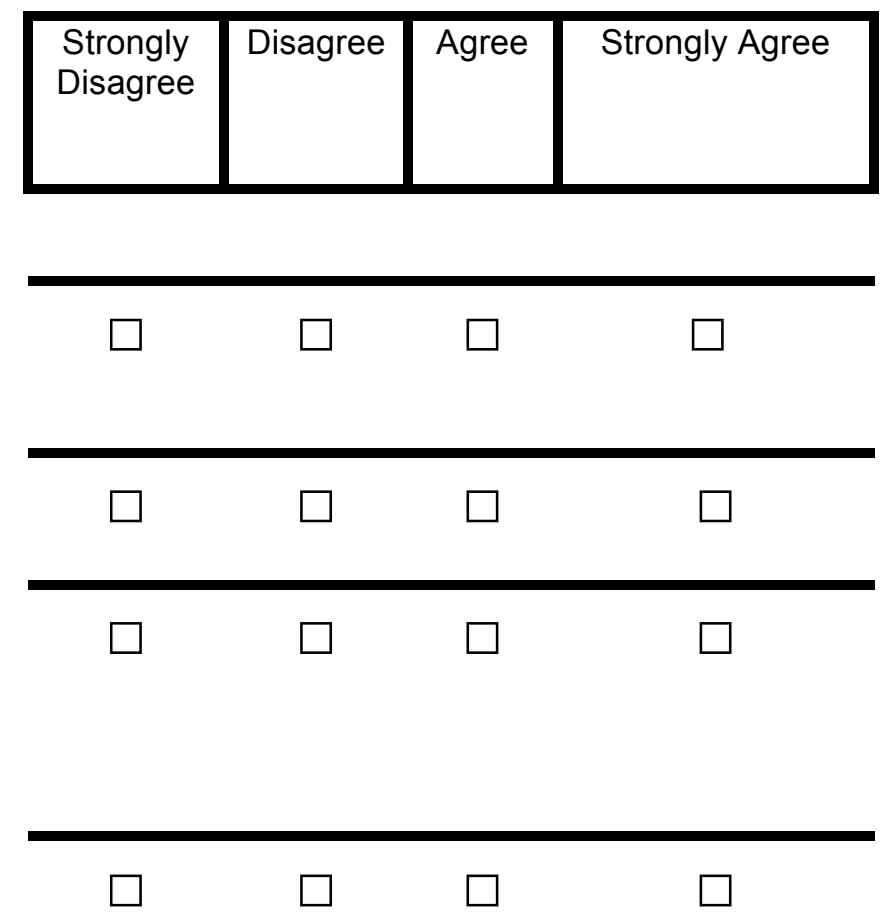

If you would like to make comments, please print them on the back but do not sign your name as I do not want to be able to identify you!

Comments: 